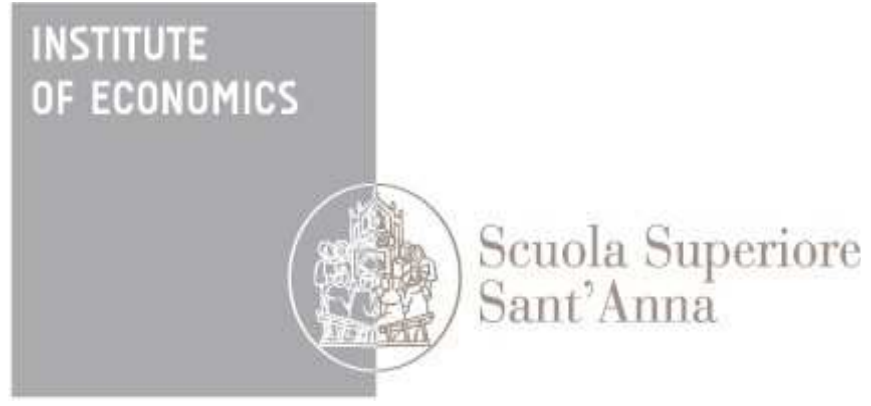

LEM | Laboratory of Economics and Management

Institute of Economics

Scuola Superiore Sant'Anna

Piazza Martiri della Libertà, 33 - 56127 Pisa, Italy ph. +3905088.33 .43$

institute.economics@sssup.it

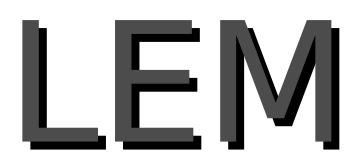

Working Paper Series

\title{
Going Up and Down: Rethinking the Empirics of Growth in the Developing and Newly Industrialized World
}

Francesco Lamperti ${ }^{\circ}$

Clara Elisabetta Mattei ${ }^{\circ}$

${ }^{\circ}$ Institute of Economics, Scuola Superiore Sant'Anna, Pisa, Italy

2016/01 January 2016

ISSN(ONLINE) 2284-0400 


\title{
Going Up and Down:
}

\section{Rethinking the Empirics of Growth in the Developing and Newly Industrialized World}

\author{
Francesco Lamperti* ${ }^{* 1}$ and Clara Elisabetta Mattei ${ }^{2}$ \\ ${ }^{1,2}$ Institute of Economics and LEM, Scuola Superiore Sant'Anna (Pisa)
}

this version: January 2016

\begin{abstract}
Growth dynamics are remarkably heterogeneous, in particular when one focuses on developing countries. Economic miracles and failures are embedded within extended phases of either growth or decline. We propose a methodology and a taxonomy that will characterize countries' growth patterns on the basis of the sequence of regimes they experience. In particular, we emphasize the difference between expansionary and recessionary regimes and, after classifying the growth pattern of all 123 developing countries in our dataset, we explore cross-sectional empirical regularities which emerge during upward and downward growth phases. Results show that expansionary regimes are associated with convergence and positive correlation between growth and (short run) volatility. On the contrary, in recessionary regimes, poorer countries face deeper failures and a negative correlation between growth and volatility is found, signifying that output fluctuates less around the trend during strong rather than mild recessions. Finally, we discover that regimes of growth and recession show similar average length (about 16 years). Although recessions on average are remarkably pronounced (14\% loss), during expansions the magnitude of growth is much larger.
\end{abstract}

JEL codes: O11, O40, O47

Keywords: growth, structural breaks, expansionary and recessionary regimes, convergence

\footnotetext{
*Corresponding author: Francesco Lamperti, piazza Martiri della Libertà 33, 56127, Pisa (Italy), email address: f.lamperti@sssup.it. The authors want to thank Flavio Calvino, Claude Diebolt, Giovanni Dosi, Andrea Mario Lavezzi and Andrea Roventini for useful comments and suggestions. All the shortcomings are our own.
} 


\title{
1 Introduction
}

\author{
"The advance occurred very slowly over a \\ long period and was broken by sharp \\ recessions. The right road was reached and \\ thereafter never abandoned, only during the \\ eighteenth century, and only by few \\ privileged countries. Thus, before 1750 or \\ even 1800 the march of progress could still \\ be affected by unexpected events, even \\ disasters"
}

- Braudel (1973 p. xi)

Have things changed nowadays with respect to past centuries? Probably not. In developing and newly industrialized countries growth dynamics are still affected by fluctuations between fabulous take off and terrible depressions, whose sequences are far from homogeneous. Over the last ten years, many studies of economic growth have moved from explaining average trends in long-term growth to studying the determinants of accelerations and collapses. Very few countries (essentially those in the OECD) have experienced a long phase of almost constant growth. In all other countries, the dynamics appear segmented into various regimes of recession, stagnation and expansion.

One of the first attempts to focus on the heterogeneity of growth patterns, both within and across different countries, is provided by Pritchett (2000). The author calls for greater attention to changes in growth rates and implicitly emphasizes the importance of regimes characterizing specific phases of long run dynamics. This paper builds on this concept to characterize the long run dynamics of 190 countries, distinguishing between regimes of expansion and regimes of recession. Regimes are identified through the detection of structural breaks in countries' growth dynamics. Subsequently we describe them as expansionary or recessive on the basis of the sign $(+/-)$ of the trend estimated in the period between the two breaks.

Certainly, the business cycle literature has explored the different functioning of economies in good and bad times (for example Auerbach and Gorodnichenko, 2012a b Ferraresi et al. 2014, Fazzari et al., 2015). Yet the literature has given little attention to differences between empirical regularities in expansionary and recessionary phases. The latter are quite frequent, especially in the non OECD countries, and last on average as long as those of expansion (around 16 years) $!^{1}$

Although patterns of growth are strongly heterogeneous across countries, there has been no attempt

\footnotetext{
${ }^{1}$ Of course, we do not confuse the up and downswings of the business cycles with what we call expansions and recessions; the latter refer to the tendency of the economy to grow or decline for periods that are larger than 5 years and are located between two structural breaks. This distinction differentiates our work from Cerra and Saxena (2008), in which crises that are part of the two year average business cycle are considered. Remarkably, we find evidence in line with theirs, even if we focus on longer regimes rather than around trend movements. Note that, according to the NBER business cycle chronology and other scholarly contributions (Diebold and Rudebusch, 1992 Filardo and Gordon 1998) downturns and upswings in the US do not usually exceed 30 or 50 months, respectively. This allows us to reasonably assume that business cycle durations are even lower in less developed countries.
} 
to make a clear-cut distinction between sequences of positive and negative growth phases. Hausmann et al. (2005) examine features and determinants of accelerations, while Ben-David and Papell (1998); Hausmann et al. (2008); Reddy and Minoiu (2009); Cuberes and Jerzmanowski (2009) those of slowdown and collapses. Jones and Olken (2008) try to analyse both. Shifting attention from the aggregate economy to the contribution that different sectors provide to acceleration phenomena Timmer and de Vries (2009) analyses a variety of great growth episodes in Latin America and Asia. All these contributions shed different light on the likelihood, duration and causes of both miracles and failures. Yet, they pool all episodes of interest together, without differentiating what happens to the dynamics of growth before such episodes take place. In addition, many of these studies do not isolate turning points (i.e. points where growth rates change the sign) from other variations in growth rates. The perplexing aggregate result is to consider the Asian tiger take-offs as a similar phenomenon to Argentina's post 2001 default recovery. In a series of papers Calvo (Calvo, 2003, 2005, Calvo et al. 006a|b) addresses issues linked both to accelerations and decelerations. By concentrating on a very specific form of output collapse, he and his co-authors are able to take advantage of the similarities between comparable episodes. Hence their results cover only a narrow range of growth shifts. Jerzmanowski (2006) analyses transition dynamics most extensively, allowing for countries to switch among different growth regimes on their development paths. However, this work focuses on single shifts, losing sight of the overall patterns of growth of developing countries. Furthermore it finds transition probabilities from sustained growth to recession that are surprisingly small. Recently, Morier and Teles (2015) propose an elegant time-varying Markov-switching approach to study growth dynamics. However, they focus their attention on three states only (growth, high growth and stagnation), forgetting completely about the long phases of recession experienced by many developing countries.

This paper proposes a methodology and a taxonomy to characterize growth patterns of almost every country for which data is available. Such a taxonomy is built on the possible sequences of expansionary and recessionary regimes across countries' structural breaks. Each category of our original taxonomy is then explored in detail. We show that there are qualitative and relevant differences between the growth patterns of industrial and developing countries. While the former experience almost a linear growth dynamic the latter undergo more extreme accelerations and decelerations. In addition, we discern and describe the cross country empirical evidence which emerges during phases of prolonged positive and negative growth. We find that empirical regularities in recessionary regimes are opposite to those in expansionary ones. The latter are associated with convergence and positive correlation between growth and (short run) volatility. However, in recessionary regimes poorer countries face deeper failures and a negative correlation between growth and volatility is found, signifying that output fluctuates less around the trend during strong rather than mild recessions.

In sum, in this essay we classify heterogeneous growth patterns and show regularities that emerge in the phases of growth and recession. Our approach and findings are attuned with Dosi et al. (1994). The authors propose a different paradigm with respect to the standard growth model. They account for growth 
and development as a multifaceted process demanding the investigation of conditions allowing growth to take off and to be self-sustained. In this framework, phenomena of convergence and divergence can be analysed in accordance with important historical evidence. For example this new paradigm accounts for the instability of growth performance in each country over different periods and the "leap-frogging" that sometimes occurs in international economic leadership. Our concept of regime-convergence, which implies catching up within specific phases of growth dynamics, is sensitive to such historical episodes.

The implications of a serious account of deeply unstable growth patterns, where expansions and contractions generate different, possibly opposite, cross country dynamics, are pervasive. First of all, international policy should take into account that, in a comparative setting, poorer countries are those most adversely affected by the entrance in long phases of recession: they tend to fall behind even more and exhibit larger drops in output than those which are richer. In short, while poorer catch-up in good time, they suffer more in bad ones. Therefore, the identification and prevention of turning points becomes crucial. As underlined in Hausmann et al. (2008), the phenomena of deep and prolonged recessions, which, we add, alternate to often extraordinary growth, constitute a real challenge for macroeconomic theory. At the very least, it suggests that a vision of economic fluctuations around a stable and growing level of potential GDP is problematic for understanding the long run economic growth of the non-OECD countries. Scholars should consider models that address non-linear growth dynamics, unexpected shifts and long (also very long) and deep (also very deep) recessions. Growth econometrics should account for these features. Pritchett (2000) shows how the existence of shifts in growth dynamics cast serious doubts on the validity of any growth regression in the fashion of Barro (1991) or Mankiw et al. (1992). Moreover, if we admit that some covariate (for example initial income) might have a non-linear effect on growth, and that shifts occur between regimes of positive to negative growth and vice-versa, then also standard panel techniques (for example, Islam, 1995) might be inappropriate and time-varying coefficients should be accounted for 2

The paper is organized as follows. Section 2 describes our data and methodology. We put forth incontrovertible evidence that calls for a new approach in the study of the phenomenon of growth for the developing and newly industrialized countries (from now on NI countries for abbreviation); a linear growth model does not suffice. Section 3 is focused on our empirical findings. In section 3.1 we appraise Pritchett (2000)'s work by adding 45 countries and a decade of growth experience. We argue that his focus on only one structural break is not robust and still inadequate to meaningfully characterize growth dynamics. In section 3.2 we present our original taxonomy, which provides an informative summary of the heterogeneity of growth patterns; section 3.3 discusses cross-country empirical evidences, highlighting the structural differences between expansionary and recessionary regimes, with a particular focus on growths' volatility and convergence. Finally, section 4 concludes the paper.

\footnotetext{
${ }^{2}$ On questions relted to the econometrics of growth see also Durlauf et al. (2005).
} 


\section{Data and Methods}

\subsection{Dataset and Econometric Approach}

We use data from the Penn World Table 7.1, converted according to 2005 PPP. In particular, we focus on the chain-linked real GDP per capita for 190 countries. The range of data lies in the interval 1950 2010. To distinguish between developing/NI and industrial countries, we consider the latter as members of OECD, provided that they joined before 20103

From a methodological point of view we identify the single major shifting point in the data for all countries in our sample and, subsequently, we also allow for two structural breaks. A couple of remarks are requisite. First, we buy Pritchett (2000)'s argument questioning the role and the power of tests identifying shifts in the growth's dynamics of different countries $4^{4}$ Our aim is to provide a convenient and informative summary of the heterogeneity of growth patterns rather than test whether regimes are identical or not. In addition, we argue that there is a simple but fundamental difference between periods of expansion and periods of recession, without the need to test whether growth rates differ from a statistical viewpoint. A country is becoming richer in one case, and poorer in the other. This is increasingly the case the longer the growth regime we consider. Moreover, we confine our analysis to the identification of two structural breaks for two reasons. In the first place, in the growth literature, the studies that use statistical tests or try to conveniently fit growth patterns, rarely identify more than two breaks per country (for example, the average in Cuberes and Jerzmanowski, 2009, is 1.8 breaks per country, while it is 1.52 in Jones and Olken, 2008). Secondly, we aim to provide a taxonomy for growth patterns that is more refined than the one offered by Pritchett (2000), yet still displays a reasonable number of categories. ${ }^{5}$

Our approach relies on the interpretation of macroeconomic quantities as segmented trend processes with infrequent shifts (Gallant and Fuller, 1973; Rappoport and Reichlin, 1989). We proceed as follows. For each country, we run a simple trend regression model and, in addition, we estimate the following two models

$$
\log \left(y_{t}\right)= \begin{cases}a_{1}+b_{1} t+\epsilon_{t}, & t \leq t^{*} \\ a_{2}+b_{2} t+\epsilon_{t} & t>t^{*}\end{cases}
$$

and

\footnotetext{
${ }^{3}$ Note that not all 190 countries have the same starting date; when comparing our results with Pritchett (2000) we follow its criteria and select 1960 as starting date, include all countries with at least 25 years of data, and add Malta and Cyprus in the set of industrial countries while we exclude Turkey; in all other exercises we consider the largest set of data available for each country.

${ }^{4}$ Note that the gold standard for structural breaks' detection is the Bai and Perron (1998, 2003)'s methodology. As remarked in Jones and Olken (2008) such an approach is very good at identifying large shifts but tends to neglect not so pronounced ones. To the contrary, we are interested in characterizing and summarizing growth patterns independently of the magnitude of accelerations and decelerations. See also Hausmann et al. (2005. 315).

${ }^{5}$ Obviously, the greater the number of breaks we identify, the larger the set of possible combination of behaviours across regimes.
} 


$$
\log \left(y_{t}\right)= \begin{cases}a_{1}+b_{1} t+\epsilon_{t}, & t \leq t_{1}^{*} \\ a_{2}+b_{2} t+\epsilon_{t} & t_{1}^{*}<t \leq t_{2}^{*} \\ a_{3}+b_{3} t+\epsilon_{t} & t>t_{2}^{*},\end{cases}
$$

where $y_{t}$ is real GDP per capita. Such an estimation is performed for each $t \in\left[t_{\text {in }}+5 ; t_{\text {fin }}-5\right]$, where $t_{i n}$ is the starting year of the sample and $t_{f i n}$ is the last one. Then we select the points in time that maximise the weighted average of the RSS (Residual Sum of Squares, that is, the numerator of the $R^{2}$ goodness of fit measure) across all regimes (two in the case of model (1) and three in the case of model (2)) and use their lengths as weights. Such points are those that best fit the shifts in the growth dynamics, thus we take them as our structural breaks. Note that for model (2), we also check that the distance between the two breaks (or one break and sample's extrema) has to be at least 5 years. If this is not the case, then we estimate only model (1). We choose not to impose a priori a minimum distance between the two breaks because we want them to be those maximizing the fit of our model with the data. Hence, we guarantee that our two breaks are points that best summarize countries' growth patterns. If the distance between the two breaks is lower that 5 years then we do not consider such interval a growth regime. Indeed we interpret it as a consequence of business cycles and therefore, we do not account for it in the characterization of growth 6

\subsection{Preliminary Evidence}

Now let us report some evidence which establishes the need to characterize growth pattens in a different way with respect to existing attempts, especially for developing countries. First, there are relevant differences between industrial and developing/NI countries. Such differences go beyond the absence of convergence and the fact that OECD countries still tend to exhibit average growth rates that are similar or even higher than developing countries. (See Table 1 and compare first and second columns for the two categories. The GDP per capita of industrial countries has grown by a factor of 4.4, while the one for developing countries by only 3.6).

More importantly non OECD countries experience growth dynamics that are qualitatively different from industrial countries. Firstly, they face more extreme accelerations or decelerations. Table 1 shows that for both categories of countries the highest level of per capita GDP is achieved in the last year of our sample, that is, 2010. However, the last column indicates that the ratio between the final level of GDP per capita and the minimum level is remarkably higher for developing countries (the median shows that it is almost twice as much), indicating that they have experienced much larger slowdowns than industrial countries.

\footnotetext{
${ }^{6}$ Notice that if we also tried to repeat our exercise discarding all regimes with length lower than 4,5 or 6 years and results are completely unaffected; see also tables 11 and 12
} 
Table 1: GDP per capita statistics (2005 PPP) for the period 1960-2010

\begin{tabular}{lcccc}
\hline & GDP p.c. - Initial & GDP p.c.- Final & Final/Maximum & Final/Minimum \\
\hline developing and newly industrialized countries & & & & \\
Mean & 2020 & 7284 & 0.91 & 4.43 \\
Median & 1136 & 3793 & 1.00 & 2.48 \\
Standard deviation & 2528 & 10126 & 0.16 & 5.38 \\
& & & & \\
industrial countries & & & & 5.53 \\
Mean & 7355 & 32795 & 0.95 & 4.85 \\
Median & 6647 & 33347 & 0.96 & 3.16 \\
Standard deviation & 3858 & 12384 & 0.05 & \\
\hline
\end{tabular}

Figure 1 further proves that the dynamics of growth for OECD and non-OECD countries are at odds. We randomly selected two industrial and two developing/NI countries and we plotted their logged GDP per capita against time. While for US and Italy the dynamics are almost linear, in the case of Afghanistan and Bolivia long recessions follow long accelerations or vice-versa, and not only once. If we were to select other sets of countries almost nothing would change 7 The point we would like to stress is that decelerations and accelerations can be of different kinds. For developing countries, what matters is that periods of large positive growth tend to follow periods of large negative growth or vice-versa. Furthermore these periods are not as short-lived as one could expect by having in mind what happens in OECD countries.

GDP over time - USA

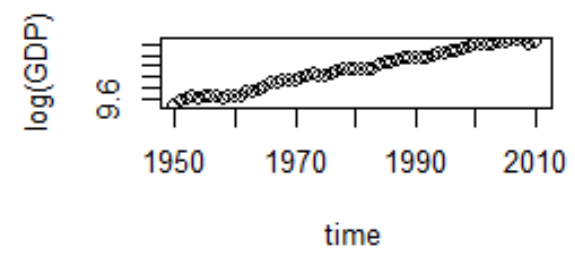

GDP over time - AFG

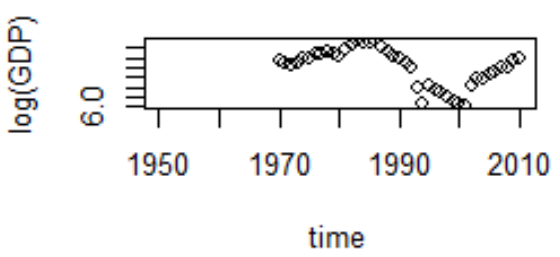

GDP over time - ITA

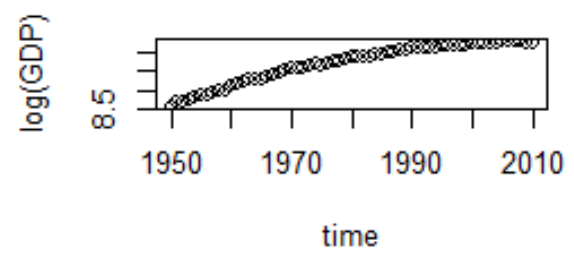

GDP over time - BOL

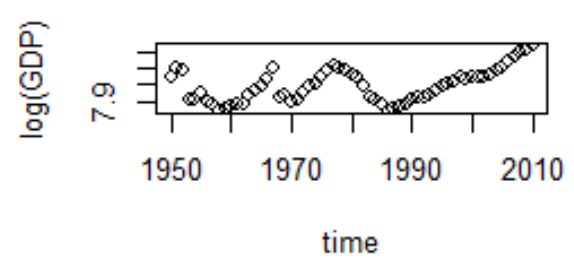

Figure 1: GDP behaviour in selected countries: OECD vs Developing

To further show that the process of growth is likely differ in developing and developed countries we draw on a well known empirical regularity: past growth has been shown to correlate poorly with future one. Easterly et al. (1993) find a rather low cross period correlation in relative growth rates (around 0.3)

\footnotetext{
${ }^{7}$ Note that there are some exceptions; for example, Japan experienced a period of negative growth in the second half of the 90s; however it was a quite peculiar case (Krugman et al. 1998), known with the name of The lost decade and also forerun by a large Earthquake in 1995 .
} 
and emphasize the role of good (and bad) luck. A similar evidence is found in Durlauf et al. (2005), who report greater correlations for developed countries. Table 2 contains results for developing and OECD countries obtained with our data, which include an additional decade of growth experiences 8

Table 2: Growth Rates Correlations Across Decades

\begin{tabular}{cccccc|ccccc}
\hline \multicolumn{3}{c}{ OECD } & \multicolumn{5}{c}{ Developing } \\
\hline & 60.70 & 70.80 & 80.90 & 90.00 & 00.10 & 60.70 & 70.80 & 80.90 & 90.00 & 00.10 \\
\hline 60.70 & 1 & & & & & 1 & & & & \\
70.80 & 0.405 & 1 & & & & 0.203 & 1 & & & \\
80.90 & 0.223 & 0.365 & 1 & & & 0.126 & 0.223 & 1 & & \\
90.00 & -0.224 & -0.043 & 0.315 & 1 & & -0.011 & 0.173 & 0.142 & 1 & \\
00.10 & -0.164 & -0.116 & 0.335 & 0.437 & 1 & -0.069 & 0.086 & 0.040 & 0.498 & 1 \\
\hline
\end{tabular}

Cross period correlations are in line with previous studies and their magnitude is much lower for developing countries in the majority of cases. Obviously, this also implies that the tendency for which countries that appear to catch up in one period, fall behind in another one is exacerbated in the group of developing economies 9

Growth miracles and failures are typical features of developing and newly industrialized countries. Table 3 collects best and worst growth performances across our sample for each decade from 1970 to 2010. All episodes but one (Korea in the 80s) has been registered in developing countries. The nineties have seen both largest growth episodes and deepest recessions; the latter have decreased in their magnitude during the first decade of the new century. Afghanistan offers a peculiar example: in the nineties it exhibited one of the worst failures ever, followed by the fourth largest expansion in the years 2000s. The important challange for growth theory is to explain these kinds of patterns 10

Moving beyond single cases, which might be isolated, one may wonder how frequently turning points occur in growth dynamics. In order to investigate this issue appropriately we must single out points characterizing regimes' change; hence we can classify the different sequences of regimes. This is exactly what we will do in the next section. A simpler but insightful approach consists of looking for changes in the sign of average growth rates across decades. Figure 2a reveals the results of this analysis for the period 1970-2010.

Almost $70 \%$ of developing countries have experienced, at least once, a transition from a ten year regime of negative growth to an equally long regime of expansion or vice versa. Interestingly, the same happened for 1 out of 5 industrial countries. Therefore, on aggregate, $60 \%$ of countries in our sample faced a change of sign. Figure $2 \mathrm{~b}$ shows the distribution of yearly average growth rates for countries with

\footnotetext{
${ }^{8}$ Notice that we removed the so-called Asian tigers (Hong Kong, Singapore, Taiwan and South Korea) from the sample of developing countries due to their well know behaviour of sustained growth characterizing their last decades, which makes them outliers with respect to the group of other developing countries.

${ }^{9}$ Notice that this feature can be confirmed by the inspection of another statistic. If one compares the mean autocorrelation coefficient for the process growth in developed countries with the corresponding one for developing countries find a ratio of 2.05 to 1 and 2.00 to 1 for lags corresponding to 1 and 5 years respectively.

${ }^{10} \mathrm{~A}$ serious case study must consider, in addition, that Afghanistan's territory has experienced uninterrupted conflicts from 1987 to 2008; the intensity of such conflicts has not changed over time (Gleditsch et al. 2002, Harbom et al. 2008).
} 
Table 3: Growth miracles and failures, 1970-2010

\begin{tabular}{|c|c|c|c|c|c|c|c|}
\hline \multicolumn{8}{|c|}{ Best Growth Perfomances (\%) } \\
\hline \multicolumn{2}{|l|}{ 70's } & \multicolumn{2}{|l|}{80 's } & \multicolumn{2}{|l|}{ 90's } & \multicolumn{2}{|l|}{ 00's } \\
\hline Botswana & 9.38 & Korea & 8.43 & Equat. Guinea & 24.70 & Azerbaijan & 14.15 \\
\hline Malta & 9.36 & Maldives & 7.66 & Bosnia Herz. & 14.43 & China & 9.71 \\
\hline Romania & 9.24 & China & 7.44 & China & 9.35 & Kazakhstan & 9.62 \\
\hline Macao & 8.07 & Botswana & 7.00 & Chile & 6.33 & Afghanistan & 9.38 \\
\hline \multicolumn{8}{|c|}{ Worst Growth Performances (\%) } \\
\hline \multicolumn{2}{|l|}{ 70's } & \multicolumn{2}{|l|}{ 80's } & \multicolumn{2}{|l|}{ 90's } & \multicolumn{2}{|l|}{ 00's } \\
\hline Cambodia & -6.40 & Liberia & -8.18 & Zaire & -9.14 & Eritrea & -3.18 \\
\hline Lebanon & -4.70 & Brunei & -6.02 & Afghanistan & -8.95 & Zimbabwe & -2.06 \\
\hline Kiribati & -4.58 & Trin. and Tob. & -5.78 & Sierra Leone & -6.74 & Liberia & -1.56 \\
\hline Chad & -4.33 & Bahrain & -4.93 & Serbia & -6.33 & Côte d'Ivoire & -1.39 \\
\hline
\end{tabular}

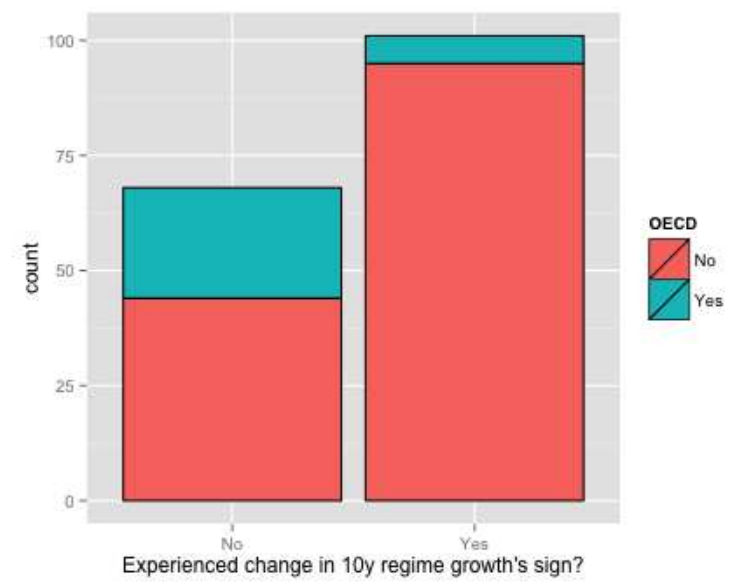

(a) Turning points in growth regimes

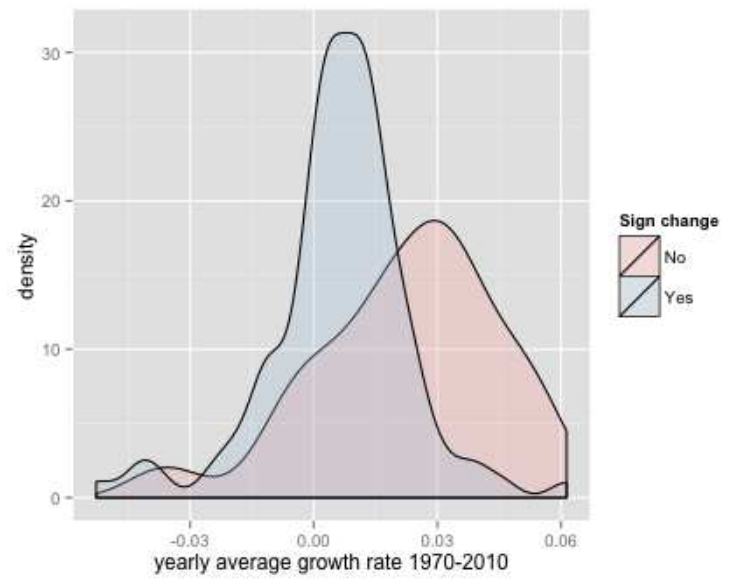

(b) Growth in countries with and without turning points

Figure 2: Growth and turning points

and without such characteristic. Obviously enough, those with at least one change of sign tend to grow at slower paces, meaning that patterns of ups and downs lead to remarkably different long run growth performances with respect to those which always expand 11

\section{Growth patterns and growth instability}

In this section we perform three exercises. First, we take the taxonmy of Pritchett (2000) and re-evaluate it by adding 45 countries and a decade of growth experiences. Such an increase is remarkably relevant and corresponds to $25 \%$ of the total sample length and to more than $40 \%$ of total observations. We show that the original classification is neither robust nor adequate enouph to summarize growth patterns, in particular for developing/NI countries. Second, we propose and discuss a new attempt to classify growth

\footnotetext{
${ }^{11}$ Only two countries exhibit negative average growth across all four decades, namely, Central African Republic and Madagascar.
} 
regimes and, finally, we analyse some implications for the debate on convergence.

\subsection{Updating hills, plateaus, mountains and plains}

In his seminal paper Pritchett identifies one break for each country, thereby obtaining 111 breaks. He then proposed a taxonomy to characterize growth patterns on the basis of the average growth rates before $\left(g_{1}\right)$ and after the break $\left(g_{2}\right){ }^{12}$ We briefly recall it. He identifies the following six categories.

$\begin{array}{cccc}\text { Pritchett } & \text { (2000)'s taxonomy } & g_{1}(\%) & g_{2}(\%) \\ \text { Steep Hills } & g_{1}>3 & g_{2}>3 \\ \text { Hills } & 1.5<g_{1}<3 & 1.5<g_{2}<3 \\ \text { Plateaus } & g_{1}>1.5 & 0<g_{2}<1.5 \\ \text { Mountains } & g_{1}>1.5 & g_{2}<0 \\ \text { Plains } & g_{1}<1.5 & g_{2}<1.5 \\ \text { Accelerators } & g_{1}<1.5 & g_{1}>1.5\end{array}$

Founding such taxonomy on a single break, each country's behaviour is summarized by what happens within two regimes only. On the one hand this approach poorly fits with patterns like those in the second row of Figure 1. On the other, it might fail to represent growth of OECD countries, where a linear trend is most likely to be the best characterization of the long run dynamics ${ }^{13}$ In addition, little or no attention is devoted to turning points (or growth reversals). Mountains represent the only category capturing a change in the sign of growth across the two regimes, yet are conditional on the fact that the upward side is remarkably steep. Indeed, a country like Venezuela, with a mild positive growth in the first regime and a slight recession in the second, falls in the same category (Plains) as Central African Republic, which instead experiences a remarkable negative growth in both periods. While Pritchett (2000) considers a category that describes positive to negative turning points, Pritchett's taxonomy completely neglects the need to address the opposite shift. The latter could be one of the most interesting issues for growth theory ${ }^{14}$

We now show that, a decade after, distribution of countries along (Pritchett, 2000)'s taxonomy is everything but robust. Figure 4 reports histograms using both Old and New data.

It is clear that the new distribution is remarkably different. We recall that, in this classification, each country is fully characterized by its major shifting point (structural break) in the growth dynamics. Only 38 out of 111 countries did not experience a "jump" from one category to another, confirming that in the last 10 years the majority of them experienced shifts large enough to alter their growth characterization. This evidence is in line with Jones and Olken (2008) and stresses that patterns of growth are characterized by a variety of starts and stops, which have affected an ample number of countries even in the last decade. Let us briefly describe this change in classification. First, Pritchett

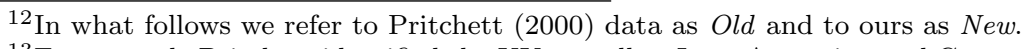

${ }^{13}$ For example Pritchett identified the UK as well as Iraq, Argentina and Congo among others, as a mountain even though it is quite hard to hypothesize that they really exhibit similar patterns of their per capita GDP. Figure 11 in the Appendix documents this.

${ }^{14}$ We recall that attempts to explain growth accelerations do exist starting from Hausmann et al. (2005), but they only look at relevant and stable increases in growth rates, without distinguishing, in practice, between what happens in taking-off economies with respect to recession-to-expansion or deep-to-mild recessions shifts.
} 

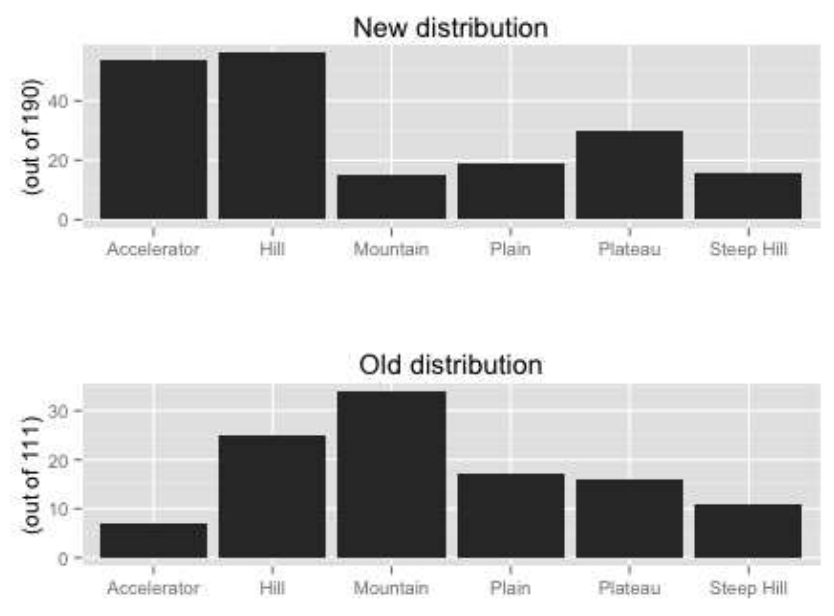

Figure 3: Countries' distribution along Pritchett's taxonomy: New and Old Data

(2000) finds that the relative majority of countries are Mountains, that is, countries with negative growth rates after the structural break. In contrast, the new data reveals that the "mountains" category is the least relevant one in terms of frequency. Instead, we see a sharp increase in the number of countries within the Accelerators category. However, within this category 33 out of 54 countries switched from a recession to an expansion regime across the structural break, while the remaining ones experienced a take off, advancing from mild to large positive growth. A second observation concerns Steep Hill countries, whose frequency and composition (basically the Asian Tigers) is almost the same in the two cases (Old and New data) $\sqrt{15}$ Finally, noticeable heterogeneity is seen in the Plain category. Out of 19 countries, 9 experienced a turning point (3 shifting from expansion to recession and 6 the other way around). This evidence further confirms that Pritchett's taxonomy pools together very heterogeneous behaviours, which instead should be distinguished.

Before we putforth our classifactory proposal it is useful to fully examine countries' behaviour based on a single break. Such analysis sheds additional light on the pressing need to identify growth patterns on the basis of turning points. The urgency clearly emerges if one applies on the New data. Figure 4 shows a scatter plot of growth rates before the break against growth rates afterward. What matters for a country is its relative position with respect to the bisector of the first and third orthants.

The lines form a band of $+/-1$ percent (blue) and 2 percent (red) around the bisector. Countries inside the bands did not change their growth rate considerably across the break while those outside it can be categorized as decelerating and accelerating. The countries that experience a decelerating phase exhibit a decreasing growth rate across the break; they are located in the upper part of the graph. Instead, countries below the bands are the ones experiencing an acceleration phase.

At this point, two important features arise. First, most countries experience great variation across the break: relatively few cases are found within the bands. Secondly, with New data, many more countries

\footnotetext{
${ }^{15}$ Countries which are Steep Hills in both cases are Botswana, Korea, Malaysia, Malta, Singapore and Taiwan.
} 

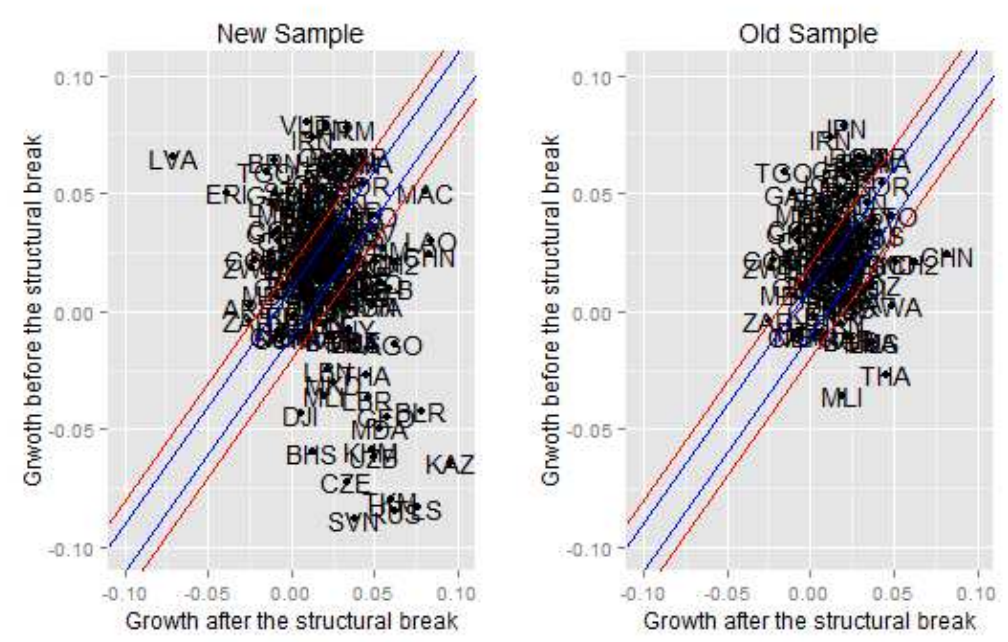

Figure 4: Country growth before and after the break

are located either in the lower right part of the graph or in the top left, meaning that, with respect to Pritchett (2000), there is evidence of a much larger number of substantial shifts between the pre and post break regimes. In addition, it is easy to notice that the majority of them are turning points.

Finally, a single break model is inadequate to characterize the heterogeneity of growth patterns from a goodness of fit perspective. Figure 5 shows the distribution of $R^{2}$ coefficients for both the single trend and single break models. It emerges that the explanatory power of the two models is similar both for OECD and non OECD countries. This hints to the fact that only one break is not enough.

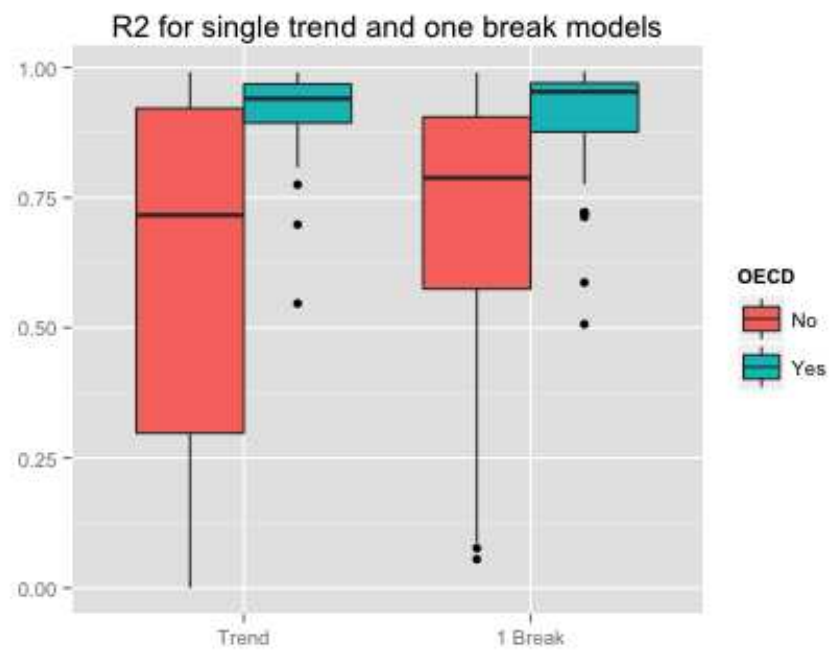

Figure 5: Single trend and one-break models' goodness of fit by OECD classification

In order to have a substantial improvement in the qualitative description of growth patterns, it is not sufficient to characterize growth with one break. Dynamics are more complex, especially for developing 
countries, where turning points and the alternation of positive and negative growth's regimes might be extremely frequent. This is why further efforts must be made to characterize the countries' growth patterns. Maintaining Pritchett's approach for the identification of shifts, we introduce an additional level of complexity through the presence of two structural breaks, and we propose a new taxonomy on the basis of the signs of growth in each distinct regime.

\subsection{Ups and Downs matter: towards a new orography of growth patterns}

\subsubsection{A new taxonomy for the dynamics of growth}

In this section we present an original categorization of growth dynamics based on the sequence of turning points experienced by each country. Figure 5 showed that a simple trend model does an extremely accurate job in fitting the long run growth behaviour of industrialized countries. For this purpose the one-break model proves to be a worse alternative. OECD countries exhibit a dynamics which is almost exponential (or linear taking logs of per capita GDP), with very small deviations from the trend over the long run (note that the median $R^{2}$ for the single trend model in industrial countries is above $94 \%$ ). For this reason we exclude OECD countries from our analysis, which is instead built on sequences of long upswings and downswings ${ }^{16}$

Developing countries tend to exhibit alternating phases of negative and positive growth that cannot be captured by only one major shifting point. The relevant phenomena are the turning points, that is, the moments in which there is an alternation between negative and positive regimes of growth (or vice versa). After having estimated model 2 for all the 128 developing countries with at least 25 years of data and identified the two relevant structural breaks for each of them, we analyse the sign of growth rates in each regime. Let $g_{1}, g_{2}, g_{3}$ be the OLS growth rates in each of the three periods identified by the breaks. Our taxonomy is defined as follows:

Table 4: A new orography of growth patterns based on turning points

$\begin{array}{cccc}\text { Growth pattern } & g_{1} & g_{2} & g_{3} \\ \text { Abyss } & - & - & - \\ \text { High Cliff } & + & + & - \\ \text { Low Cliff } & + & - & - \\ \text { Iceberg } & - & - & + \\ \text { Slope } & - & + & + \\ \text { Mount } & - & + & - \\ \text { Valley } & + & - & + \\ \text { Peak } & + & + & +\end{array}$

We chose the names of the categories on the basis of an intuitive association with the shapes of common landscape formations. The deep sea abyss surely suggests the lowest growth possible. Steep rocks at the edge of the sea, cliffs precede a drop in elevation; indeed, both categories with this name suggest a fall

\footnotetext{
${ }^{16}$ Despite the evidence that all capitalist developed economies follow a qualitative similar dynamics, the reader should not conclude that a general long run rhythm of growth exists for these countries taken as a whole. See for example the interesting discussion in Maddison (2007).
} 
in growth. Icebergs float barely above the water, but are mostly greatly recessive, while slopes exhibit a positive inclination for growth. A mount has the opposite growth trend of a valley; while it is the peak which represents the summit of a mountain, thus a country must be constantly growing to aspire to such category. All categories include at least one turning point, with the exception of Abyss and Peak. Such categories represent the extremes of our classification: a country in persistent recession (Abyss) and one continuously growing across regimes (even with different rates, the relevant aspect of a Peak is that it keeps growing). Between these two extremes we have 6 different patterns mixing expansions and recessions. It is noteworthy that the categories of Mount and Valley allow for two turning points, the former starting with a downturn and the latter, with an upturn. Our new taxonomy is appealing for two reasons. In the first place it allows us to characterize a larger and more complex set of patterns, including those in the bottom row of Figure 1 and, remarkably, it gives information on the frequency and type of transitions from recessions to expansions (and vice versa), keeping track of those previously experienced. For example, a large number of central African countries within the Iceberg category would indicate that growth dynamics have been similar within the geographical area: they are characterized by two phases of recessions and a regime of positive growth that has begun recently. In addition, we understand that such group of countries has never experienced a transition from positive to negative growth. In some respects this new taxonomy complements the qualitative description offered in Jones and Olken (2008): the authors isolated growth accelerations and decelerations for each country, while we further distinguish between up and down phases, keeping track of their order, to fully characterize long run patterns. Figure 7 shows an histogram reporting the counts of developing countries in accordance with our new taxonomy of growth patterns. Notice that our sample is composed of 123 countries. We have removed 5 because the breaks that maximize the fit of model (2) were closer together than 5 years time ${ }^{17}$

The relatively most frequent pattern is the Peak, corresponding to a country growing in each of the three regimes. Almost $60 \%$ of developing countries however experienced at least one turning point in their long run dynamics, and nearly $25 \%$ had two. Regimes of negative growth are remarkably common and can be observed in more 75 countries in the sample. Moreover, the lengths of expansive and recessive regimes are very similar: 16.7 years for the former and 16.3 for the latter, on average. Yet the magnitude of per capita output variation is much larger for positive growth phases, with an average of $+71 \%$ (with respect to the value of the beginning of each regime) contra the - $14 \%$ of recessions. Downward regimes in developing/NI countries decrease GDP per capita level less than upward ones increase it, yet the average size of output loss in those countires during recessions is considerably high, in particular if we compare them to OECD countries. For example, notice that GDP per capita in the US in 2010 was $96 \%$ of the 2007 value and the 2012 to 2007 ratio of Greek GDP per capita is 0.85 . It is clear that recessions are quite frequent, nonetheless only two observations fall in the Abyss category, which records the growth dynamics of countries that have never experienced a durable pattern of positive growth. The High and

\footnotetext{
${ }^{17}$ For clarification on our selective criterion see footnote 6. In particular, the countries we removed: Central African Republic, Côte d'Ivoire, Lebanon, Rwanda and Samoa.
} 


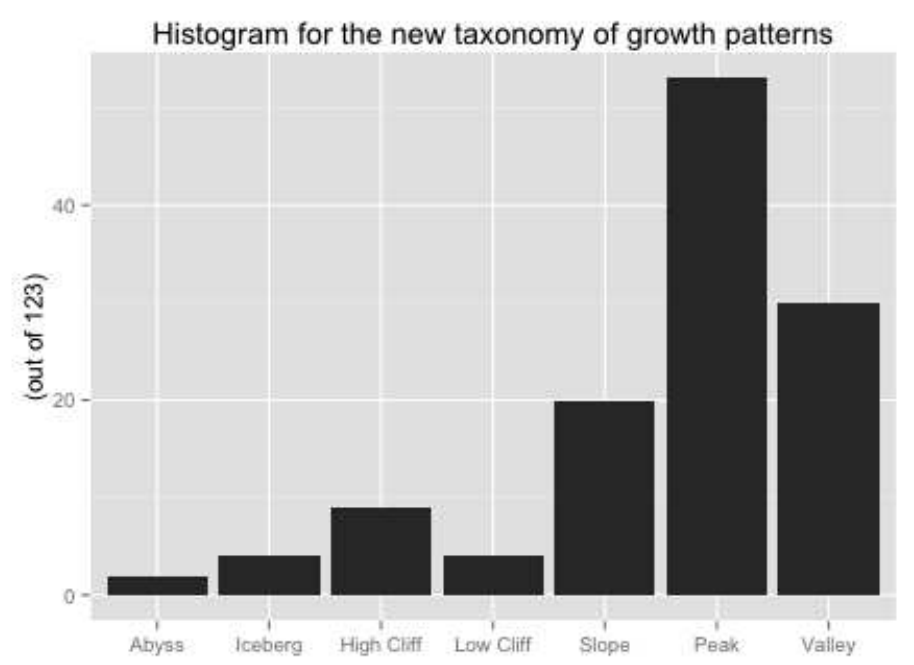

Figure 6: Counts of countries in the new taxonomy of growth patterns

Low Cliff categories also encompass a relatively small number of countries, attesting that in the most recent years developing countries are usually growing. If we take the majority of developing/NI under observation we notice that they first faced an expansionary regime, followed by an intermediate phase of negative growth, before they resumed an upward regime. This kind of pattern is exactly that of Valley countries, the second most numerous category. Our taxonomy fully captures the complex heterogeneity of growth dynamics that characterize developing countries; to better visualize this heterogeneity figure 7 shows a plot for each of the 7 categories. We note that no country fell in the Mount category.

We can also analyse our taxonomy with respect to the geographical positioning of the countries in the different categories. Some interesting features emerge. Table 5 presents all developing countries within each category of the new taxonomy we propose. The most densely populated category is surely the Peak. It is also the most heterogeneous, all continents being represented. We have 14 countries from Latin American and the Caribbean, 11 Sub-Saharan African countries, followed by 10 Asian and South Asian countries. This category is also composed, to a smaller extent, of countries from the Middle East, Europe and Oceania. It is important to note that, to the Peak group belong 3 out of 5 of the BRICS (China, India, Brazil), and three Asian tigers: Hong Kong, Singapore and Taiwan. Valley is the second most numerous category. Its members are heterogeneously distributed. It is composed of 14 Sub-Saharan African Countries, including the fourth BRIC, i.e. South Africa; 7 South American and Caribbean, 3 Middle Eastern, 2 European, and just one Asian country (Mongolia). This category comprises very different countries. Some are more developed (Venezuela and Romania, for example) while others are very poor and socio-economically distressed (Sierra Leone and Madagascar are considered the 2 most corrupt countries in Africa ${ }^{18}$ The Abyss category is constituted by Sub-Saharan African countries; this holds true also for the Iceberg category, with the exception of Haiti. High Cliffs are also mostly African

\footnotetext{
${ }^{18}$ According to the 2014 CPI index provided by Transparency International.
} 
countries, except for two Caribbean: Puerto Rico and Saint Kitts and Nevis. Low Cliffs are as well typically African, with the exception of the Caribbean Jamaica and the Asian Brunei Darussalam, which is extremely rich with respect to all other developing countries. Slope is another densely populated and geographically heterogeneous category. We have 6 in Latin America and Carebbean (Honduras, Uruguay, Bahamas, Saint Vincent and the Grenadines), 6 South Asian (Bangladesh, Bhutan, Cambodia, Maldives, Sri Lanka, Thailand), 6 Sub-Saharan African Countries (Angola, Chad, Rwanda, Mauritius, Cape Verde, Congo); 2 Middle Eastern (Lebanon, Iraq), 2 North African (Algeria and Morocco) and, lastly, Palau, an island in Oceania.

Table 5: Countries and growth patterns

\begin{tabular}{llll}
\hline & Countries within each category of growth & patterns \\
\hline Abyss & High Cliff & Valley & Peak \\
Guinea & Gabon & Nigeria & Guatemala \\
Liberia & Mali & Papa New Guinea & Guinea Bissau \\
& Puerto Rico & Peru & Hong Kong \\
Iceberg & Saint Kitts & Romania & India \\
Djibouti & Tonga & Sao Tome and Prin. & Indonesia \\
Haiti & Zimbabwe & Sierra Leone & Jordan \\
Senegal & & South Africa & Laos \\
Zaire & Low Cliff & Trin. and Tob. & Macao \\
& Brunei & Uganda & Malaysia \\
Slope & Jamaica & Venezuela & Marshall Islands \\
Algeria & Niger & Zambia & Mauritania \\
Angola & Somalia & & Micronesia \\
Bahamas & Togo & Peak & Mozambique \\
Bangladesh & & Albania & Nepal \\
Bhutan & Valley & Antig. and Barb. & Oman \\
Cambodia & Afghanistan & Argentina & Pakistan \\
Cape Verde & Bahrain & Belize & Panama \\
Chad & Barbados & Benin & Paraguay \\
Honduras & Bulgaria & Bermuda & Philippines \\
Iraq & Cameroon & Botswana & Samoa \\
Lebanon & Cuba & Brazil & Seychelles \\
Maldives & Ethiopia & Burkina Faso & Singapore \\
Mauritius & Gambia & Chile & Solomon Islands \\
Morocco & Ghana & China & Santa Lucia \\
Palau & Guyana & Colombia & Suriname \\
Rwanda & Iran & Costa Rica & Syria \\
Sri Lanka & Kiribati & Dominica & Taiwan \\
Saint Vincent & Lesotho & Ecuador & Tanzania \\
Thailand & Madagascar & Egypt & Tunisia \\
Uruguay & Malawi & Slovenia & Turkey \\
Burundi & Mongolia & Equat. Guinea & Vanuatu \\
Comoros & Namibia & Fiji & Vietnam \\
Congo & Nicaragua & Grenada & \\
\hline
\end{tabular}


GDP over time - GIN

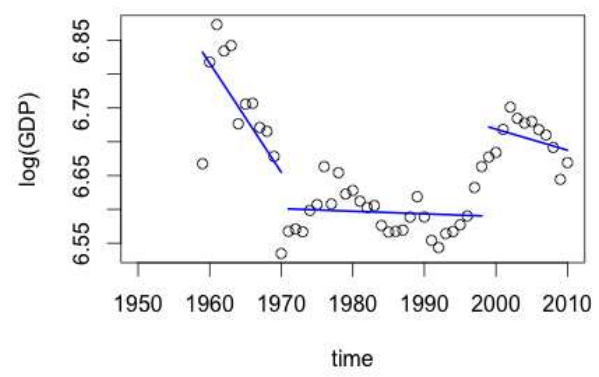

(a) Abyss - Guinea

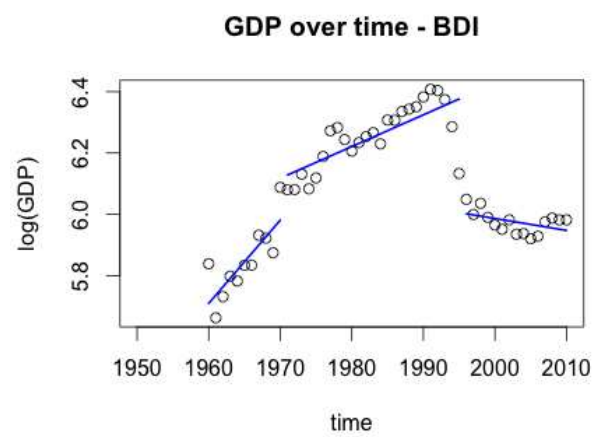

(c) High Cliff - Burundi

GDP over time - URY

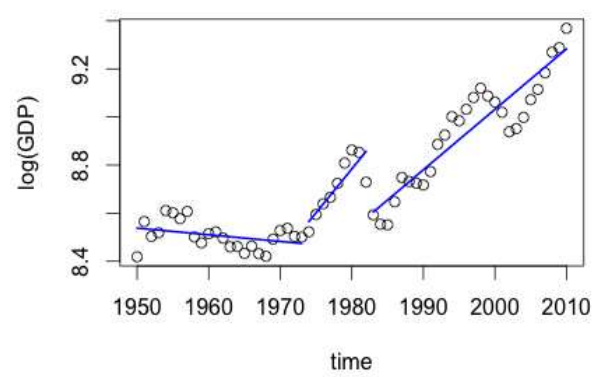

(e) Slope - Uruguay

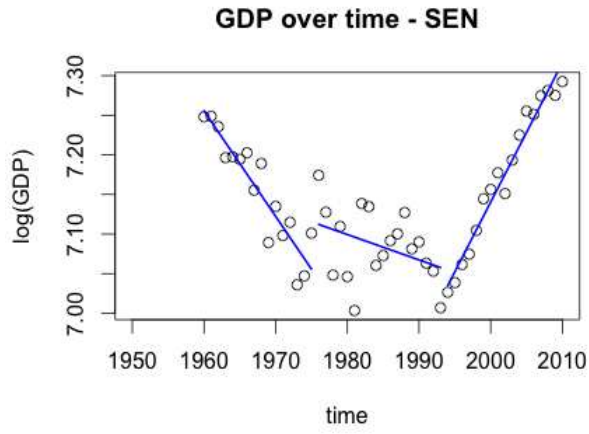

(b) Iceberg - Senegal

GDP over time - NER

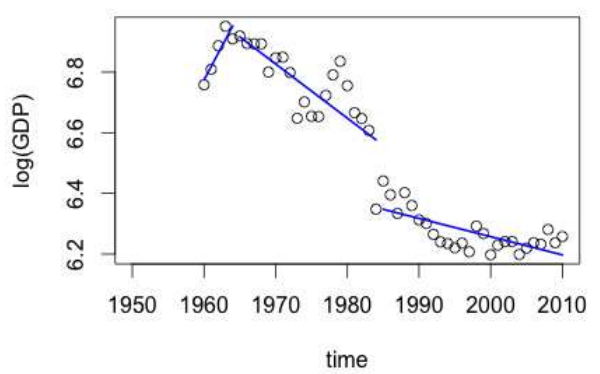

(d) Low Cliff - Niger

GDP over time - ROM

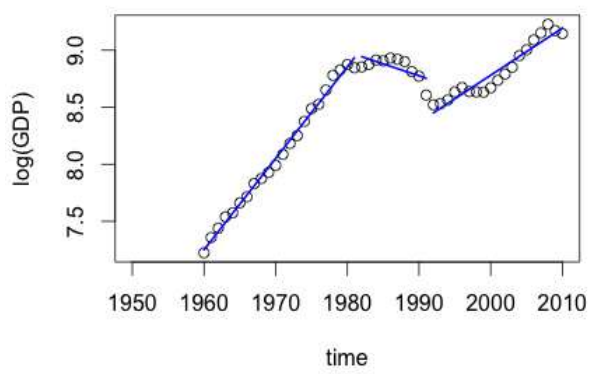

(f) Valley - Romania

GDP over time - DOM

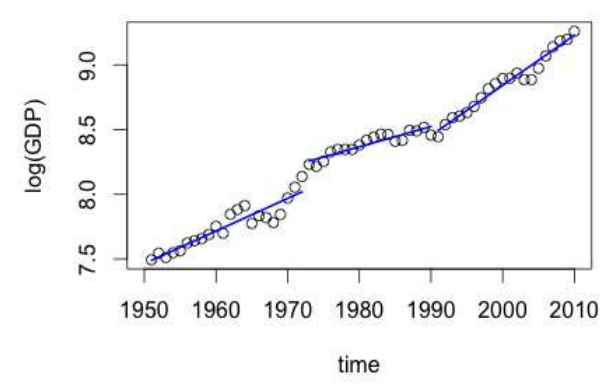

(g) Peak - Dominica

Figure 7: Plots of examples of growth patterns - one for each category 


\subsubsection{Growth patterns and their features}

Our taxonomy reveals some additional features about the diverse growth dynamics of the different categories. Table 6 reports them together with the within group means of different indicators 19 In contradiction with any theory of beta convergence (see next section), Abyss countries are those with the lowest levels of initial and final per capita output. Initially Peaks were not the richest group, however more than half of them record a starting level of per capita output higher than the median of all developing countries. It is also the group that is growing much faster than any other, with an average yearly growth rate of $2.70 \%$ and a final to initial output per capita ratio larger than 5.5. All categories displaying a number of recession regimes larger than the expansionary ones show a negative average growth over the full sample. However, those spending a larger fraction of time in recession regimes are not always associated with a lower long run growth: Iceberg countries spent $66 \%$ of total time in phases of negative growth and grew at a pace 7 times slower than Low Cliff countries which, to the contrary, are found in recession in $73 \%$ of periods. This feature can be explained by the fact that the length and magnitude of failures changed across decades and regimes. Iceberg and Low Cliff groups are characterized by opposite dynamics: a sequence of one phase of growth and two recessionary phases for the latter group and the opposite in the former.

Table 7 reports regimes' length and growth magnitude (measured as percentage variation with respect to initial regime values). The average length of first negative growth regimes is of 13.3 years opposed to the 20.1 years of the recessions found in the third regime. Despite the relevant difference in respective length, recessions in most recent decades have been by far less disruptive. They registered an average loss of per capita output of $3 \%$, one third of the $15 \%$ average loss suffered, by countries in recession during their first growth regime. This confirms the general tendency, already pointed out in table 3 of developing/NI countries facing less severe downswings in their growth patterns, even though the downturns last much longer than in the past.

A similar reasoning applies to the case of Valley and High Cliff countries; the former experienced a regime of negative growth between two regimes of expansion, while High Cliffs grew positively in the first two phases and faced a depression afterwards. The average magnitude of negative growth in the second regime corresponds to a loss of per capita output equal to $23 \%$, which is the highest recorded across the three regimes. This should help explain the fact that High Cliffs exhibit a higher average growth than Valleys even though High Cliffs experienced much longer phases of recession. Shifting our attention to the length and magnitude of expansionary phases, we report that both have increased over time. The first regime of positive growth lasted, on average, 14.6 years with a per capita GDP that increased by 57\%; the second lasted 17 years with an increase of almost $70 \%$; while the third went on for 18.6 years with an exceptionally high slump of $88 \%$. However, it is relevant to recall that the vast majority of developing countries was not able to experience such a series of growth miracles, rather, they alternated fabulous

\footnotetext{
${ }^{19}$ When presenting initial and final GDP per capita we remove Brunei from the set of Low Cliff countries since it is a very extreme outlier (values more than 25 times larger than group average) and it would bias the group's average values.
} 
Table 6: Growth pattern features

\begin{tabular}{lccccccc}
\hline & Abyss & Iceberg & H. Cliff & L. Cliff & Slope & Peak & Valley \\
\hline turning points & 0 & 1 & 1 & 1 & 1 & 0 & 2 \\
recessions & 3 & 2 & 1 & 2 & 1 & 0 & 1 \\
time in recession (\%) & 100 & 66 & 42 & 73 & 24 & 0 & 32 \\
average growth (\%) & -1.28 & -0.75 & 1.69 & -0.06 & 1.79 & 2.7 & 1.26 \\
$\mathrm{y}_{\text {in }}$ & 1043 & 2035 & 1765 & 1897 & 3389 & 2914 & 3126 \\
$\mathrm{y}_{\text {fin }}$ & 623 & 1383 & 6079 & 3244 & 6515 & 11406 & 6238 \\
$\mathrm{y}_{\text {fin }} / \mathrm{y}_{\text {in }}$ & 0.68 & 0.73 & 2.71 & 1.13 & 2.93 & 5.54 & 2.23 \\
$\mathrm{y}_{\max } / \mathrm{y}_{\min }$ & 5.16 & 2.54 & 3.56 & 1.99 & 4.02 & 5.75 & 2.81 \\
$\mathrm{~g}_{\max }-\mathrm{g}_{\min }$ & 0.76 & 0.35 & 0.53 & 0.33 & 0.84 & 0.69 & 0.79 \\
$\mathrm{sd}_{\mathrm{d}\left(g_{1}, g_{2}, g_{3}\right)}$ & .0283 & .0269 & .0298 & .0297 & .0303 & .0202 & .0379 \\
$1_{- \text {model }}(2)$ 's $\mathrm{R}^{2}$ & 0.74 & 0.53 & 0.30 & 0.59 & 0.32 & 0.22 & 0.29 \\
\hline
\end{tabular}

Note: $g_{\max }$ and $g_{\min }$ refer to maximum and minimum yearly growth rates while $\left.\mathrm{g}_{\{1,2,3}\right\}$ to average growth rates in regime 1,2 and 3 . For each country the three regimes correspond to the following periods $\left[t_{i n}, t_{1}\right),\left[t_{1}, t_{2}\right)$ and $\left[t_{2}, t_{\text {fin }}\right)$ respectively.

expansions with failures.

Table 7: Length and magnitude (average values) of expansionary and recessionary regimes.

\begin{tabular}{lcccc}
\hline Growth in & \multicolumn{2}{c}{ expansion } & \multicolumn{2}{c}{ recession } \\
\hline & length (years) & magnitude & length (years) & magnitude \\
1st regime & 14.6 & $57 \%$ & 13.3 & $-15 \%$ \\
2nd regime & 17.0 & $69 \%$ & 15.6 & $-23 \%$ \\
3rd regime & 18.6 & $88 \%$ & 20.1 & $-3 \%$ \\
\hline Note: for each country the three regimes correspond to the following periods $\left[t_{i n}, t_{1}\right)$
\end{tabular}

Such instability of growth can be analysed even within and across classes of growth patterns. We use table 6 to report three statistics: (i) the cross-section average of the difference between the maximum and minimum yearly growth rate registered for each country $\left(\mathrm{g}_{\max }-\mathrm{g}_{\min }\right)$, (ii) the standard deviation of regime growth across trends $\left(\operatorname{sd}\left(g_{1}, g_{2}, g_{3}\right)\right)$ and (iii) the complement to 1 of model $2 \mathrm{~s} \mathrm{R}^{2}$. The first and the second are direct measures of the dispersion of growth over the full time span; for this reason they are used to proxy long run instability of growth. The third can be used to indicate the strength of the fluctuations around the three trends estimated for each country. The lower the level of indicator (iii), the smaller the volatility of growth around the regime's trend. Such an indicator is quite useful since it offers an easy and direct way to measure the instability of growth while contemporaneously washing away the volatility due to structural breaks in long run trends and correcting for individual within-regime total volatility ${ }^{20}$ We will now focus on this statistic. After controlling for the category of growth dynamics, the around trend volatility is negatively related to starting levels of output. The classes of countries with low $y_{\text {in }}$ are also the ones experiencing highest short run volatility. This feature is quite evident even

\footnotetext{
${ }^{20}$ This means that given any pair of countries experiencing a regime of growth with identical fluctuations around the trend, higher volatility will be measured for the country experiencing the larger variation between regimes' initial and final output level.
} 
by looking at figure 7. A similar reasoning applies to the case of absolute growth magnitude, $y_{\text {fin }} / y_{\text {in }}$. The groups of countries facing marked growth are also those whose around-trend volatility is very low. This evidence is in line with Loayza and Hnatkovska (2004), who distinguish between long and short run volatility, and document the existence of a negative correlation between such volatilities and growth ${ }^{21}$ Notwithstanding this similarity, we do not find evidence confirming their results when long run volatility is at stake, either using (i) or (ii). It is true that looking at these relationships through the lens of our taxonomy oversimplifies the analysis, however, the summary statistics we obtain show that higher long run volatility is not associated with poor growth performances. The groups of countries that, on the whole, are positively growing yet facing one recession regime (Valley, Iceberg and High Cliffs) exhibit, on average, higher long run volatilities than the countries experiencing an opposite pattern (two recession phases and only an expansionary one) and growing much less. Previous observations on the strength of growth and recessions in the third and second regimes help justify this result.

\subsection{Regularities during Ups and Downs}

\subsubsection{Volatility}

Beyond observing instability of growth across classes we could also look at what happens within them. In particular, we focus on what happens during recessions and expansions in each of the three regimes. Obviously, by dividing the length of our sample in three regimes and looking within them separately, we can only focus on short term volatility.

Our analysis starts drawing on Castaldi and Dosi (2009) and estimating the distributions of growth rates for phases of expansion and recession. Our strategy is twofold; first we perform a non-parametric kernel estimate of the distributions to get a quick insight about their shapes and, secondly, we use the same data to fit a symmetric power exponential (or Subbotin) distribution. The idea behind these exercises is to investigate whether the volatility of growth rates differs between expansionary and recessionary phases. The use of a power exponential distribution motivated by its flexibility; its functional form is given by

$$
f(x)=\frac{1}{2 a b^{\frac{1}{b}} \Gamma\left(1+\frac{1}{b}\right)} e^{-\frac{1}{b}\left|\frac{x-\mu}{a}\right|^{b}}
$$

where $a$ controls for the standard deviation, $b$ for the shape of the distribution and $\mu$ represents the mean. When $b=2$ the distribution turns out to be a Normal one, while for $b=1$ the distribution is Laplacian. These observations are relevant because as $b$ gets smaller, the tails get heavier and the peak of the density becomes more pronounced. We are interested in whether fatter tails appear within recessionary phases with respect to expansionary ones. Before proceeding, we standardize our growth rates in a way to remove an eventual common trend component. Therefore, if $y_{t, i, h}$ is the per capita

\footnotetext{
${ }^{21}$ Loayza and Hnatkovska look at long run growth volatility using the standard deviation of yearly growth rates, while they analyse the short run volatility through the standard deviation of GDP gap with respect to the long run trend, which is unique in their analysis.
} 
GDP of country $i$ measured at time $t$ within regime $h$, we define $s_{i, t, h}^{*}=\log \left(y_{t, i, h}\right)-\overline{\log \left(y_{t, h}\right)}$, where the second term is the average over all countries within $h$. The standardized growth rate of country $i$ from $t-1$ to $t$ is simply given by $g_{t, i, h}^{*}=s_{i, t, h}^{*}-s_{i, t-1, h}^{*}$. Now, we are ready to estimate our symmetric power exponential distributions within each regime 22 Table 8 collects the results.

Table 8: Estimates of symmetric power exponential distributions

\begin{tabular}{lcccccc}
\hline Estimates in & \multicolumn{3}{c}{ expansion } & \multicolumn{3}{c}{ recession } \\
\hline \multirow{3}{*}{ 1st regime } & $a$ & $b$ & $\mu$ & $a$ & $b$ & $\mu$ \\
& 0.045 & 0.591 & 0.002 & 0.055 & 0.494 & -0.025 \\
2nd regime & $(0.002)$ & $(0.026)$ & $(0.000)$ & $(0.005)$ & $(0.044)$ & $(0.000)$ \\
& 0.046 & 0.964 & 0.016 & 0.052 & 0.893 & -0.025 \\
3rd regime & $0.036)$ & $(0.048)$ & $(0.001)$ & $(0.003)$ & $(0.064)$ & $(0.002)$ \\
& $(0.001)$ & -1.125 & 0.005 & 0.039 & 0.995 & -0.026 \\
pooling & 0.040 & 0.739 & $(0.001)$ & $(0.003)$ & $(0.126)$ & $(0.002)$ \\
& $(0.000)$ & $(0.019)$ & $(0.000)$ & $(0.002)$ & $(0.032)$ & $(0.001)$ \\
\hline
\end{tabular}

Note: for each country the three regimes correspond to the following periods $\left[t_{i n}, t_{1}\right)$, $\left[t_{1}, t_{2}\right)$ and $\left[t_{2}, t_{f i n}\right)$ respectively. The pooling label indicate estimates obtained pooling observations from the three regimes. Standard errors in parenthesis.

Results show that, independently on the regime, the parameter $b$ estimated during recessions is lower than the corresponding one obtained for expansionary phases. In addition, small standard errors suggest that the difference is likely to be statistically significant. Therefore, we report evidence that contractions display higher volatility of growth than expansions do. These insights are also confirmed by the estimates obtained pooling growth rates from different regimes. Another relevant remark applies to the size of the estimated $b$ values. In all cases but one, both for expansions and recessions, they are found to be lower than 1, indicating remarkable non-Gaussian and fat tailed distributions of growth rates. This evidence, as we further remark below, casts doubts on the validity of various t-tests that are sometimes used to investigate the determinants of growth. Figure 8 allows the graphical inspection of the distributions estimated and confirms the presence of larger growth volatility during recessions and the fat-tailed nature of growth rates 23

Now let us go back to move back from this distributional analysis of annual growth rates and focus how volatility relates to growth. We recall that, hereafter, volatility is proxied by (iii). Table 9 reports the average volatility experienced by countries in expansion and recession during each of the three regimes and their correlation with growth in the same regime. It is important to notice that we measure growth in terms of the ratio between the regimes' final and initial output per capita. This choice is driven by the necessity to account for the different length of regimes across countries, which implies that yearly average growth rates would be biased and, therefore, not good candidates to summarize the regimes' growth.24

\footnotetext{
${ }^{22}$ We use the maximum likelihood estimation procedure proposed in Bottazzi $(2004)$.

${ }^{23}$ Kernel estimates are obtained using Gaussian kernels with bandwidth 0.007 for expansions and 0.011 for recessions. Bandwidths are selected applying the rule of thumb proposed in Silverman (1986).

${ }^{24}$ If all regimes had equal length, in case we used growth rates in place of final-to-initial output ratios, we would not find differences in the correlations of 9 since growth rates result from a monotonic transformation of the final-to-initial output ratios.
} 

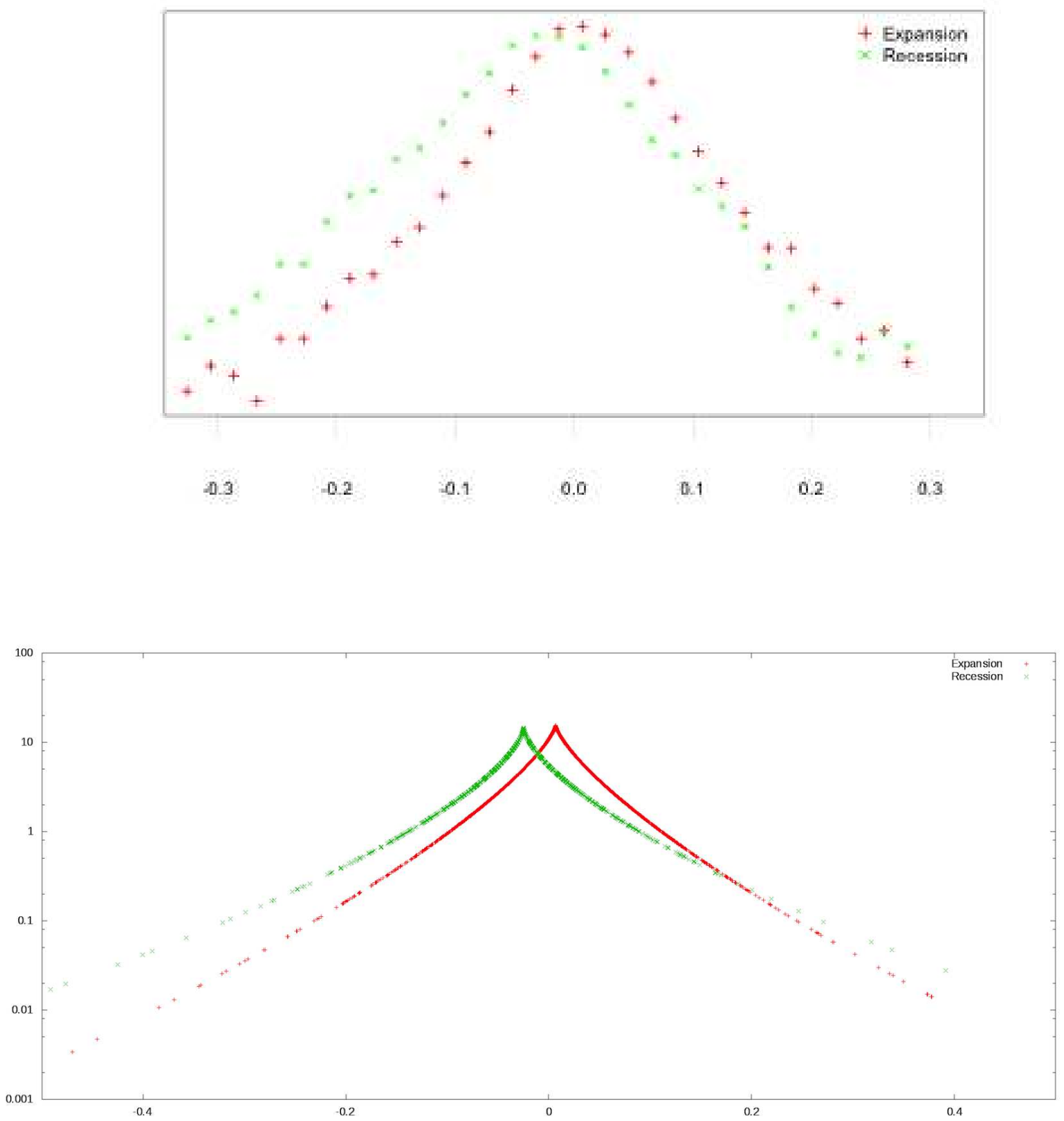

Figure 8: Empirical (top) and theoretical (bottom) distributions of growth rates for expansions (red) and recessions (green)

First, we observe that short run volatility is always much larger during downswings than upswings. On aggregate, this results in the fact that there is a negative correlation between such volatility and growth. However, by breaking down growth patterns in regimes of expansion and regimes of recession the table offers additional insights. In phases of positive growth, there is a negative correlation between 
Table 9: Short run volatilities (average values) and correlations with growth in expansions and recessions.

\begin{tabular}{lcccc}
\hline Volatility in & \multicolumn{2}{c}{ expansion } & \multicolumn{2}{c}{ recession } \\
\hline & short-run vol. & corr. with growth & short-run vol. & corr. with growth \\
1st regime & 0.27 & -0.53 & 0.63 & 0.39 \\
2nd regime & 0.30 & -0.40 & 0.43 & 0.67 \\
3rd regime & 0.21 & -0.25 & 0.57 & 0.80 \\
\hline
\end{tabular}

Note: for each country the three regimes correspond to the following periods $\left[t_{i n}, t_{1}\right),\left[t_{1}, t_{2}\right)$ and $\left[t_{2}, t_{f i n}\right)$ respectively.

around-trend volatility and growth: countries growing a lot faster do not deviate much from their long run tendency. Similarly, during deep recessions there is lower instability of growth. This, however, results in a positive correlation between short run volatility and growth during recessionary regimes; countries that face mild negative growth regimes are much more volatile than those experiencing worse depressions (notice that the correlation reaches quite high magnitudes, e.g. 0.80 in the third regime). Clearly, if one considers the whole of the developing/NI countries, there exists much fewer negative growth phases than positive ones, hence the latter prevail in the aggregate picture. Instability of growth is a feature that affects the middle range of the cross-country distribution of performance, while growth miracles and failures are usually much less volatile. This supports the evidence of a non-linear relationship between short run instability of growth and growth itself.

Summarizing, we conclude our discussion on the relationship between growth and volatility pointing out that (a) long run volatility is not associated with groups of countries growing at lower paces; rather, it seems that fast-growing groups are those exhibiting larger instability of growth over the long run; (b) short run volatility, on aggregate, is negatively correlated with growth, however (c) different patterns emerge which clearly differentiate expansionary periods from recessionary ones. Expansions are characterized by a strong positive correlation between growth and around-trend volatility. On the contrary, recessions portray a linear association between growth and around trend volatility that is less pronounced in magnitude and of opposite sign.

\subsubsection{Converge, new convergence and divergence}

Previous sections provided some evidence on the fact that groups of initially poorer countries do not grow faster in the long run, rather they have the worst performances and the largest amount of time spent in recessions. We also showed that expansionary and recessionary regimes differ in a number of aspects including length, magnitude and correlations with growth volatility. This section explores some implications of these features for convergence.

It is neccessary to clarify what we mean by convergence. As outlined in Quah (1993), there are different usages of this term in the growth literature; specific empirical implications and detection tests are linked to each of them. In this section, convergence corresponds to the following phenomenon: countries originally 
richer than average are more likely to turn below average or vice-versa. In other words, initially wealthier countries tend to grow at lower rates with respect to poorer ones. This notion of convergence is often called beta-convergence and implies a negative (conditional or unconditional, it depends on the cases) correlation between initial level of GDP per capita and growth rates across countries. Convergence more or less implies the phenomenon of developing countries catching up with OECD ones.

Prompted by a decade of extraordinary growth in almost all the developing world (as it is confirmed by our last regime), in recent years a number of contributions have concerned the possibility of a new period of convergence (Buiter and Rahbari, 2011, Rodrik, 2011, Spence, 2011, Hawksworth and Tiwari, 2011). Discussing the likelihood of this prediction goes well beyond the aim of this section; however, we present some empirical evidence to suggest that absence or presence of convergence might be driven, in aggregate, by the relative share of countries in expansion and recession.

Figure 9 separately shows the classic plot of growth rates against initial per capita output for OECD and developing countries 25 The red line is the one best fitting the data. The two graphs are remarkably different. While, for developed countries, there exists a clear-cut negative association between initial richness and magnitude of growth, this association is almost completely absent in the case of non OECD countries. Among the enormous variety of factors that differentiate industrial from developing countries one discerns their growth dynamics. As section 3.1 has shown, a $(\log )$ linear positively sloped dynamics well describes the long run growth of OECD countries; however this is not the case for the developing and newly industrialized world. Therein, we have seen that growth dynamics are strongly heterogeneous across countries, alternating phases of recession and expansion. A question arises: does the evidence of catching up change across expansionary and recessionary regimes? The answer we get is yes, evidence changes. In particular, we find two opposite behaviours: convergence during phases of positive growth and divergence during phases of negative growth.

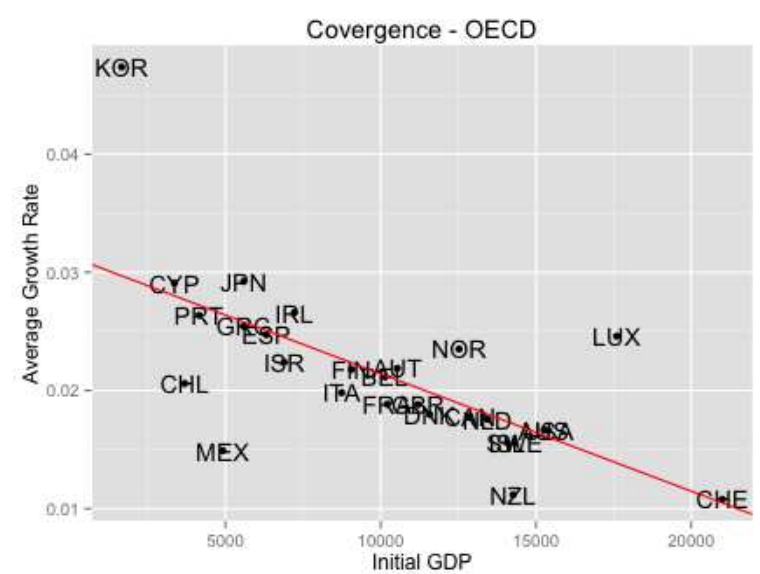

(a) Industrial (OECD) Countries

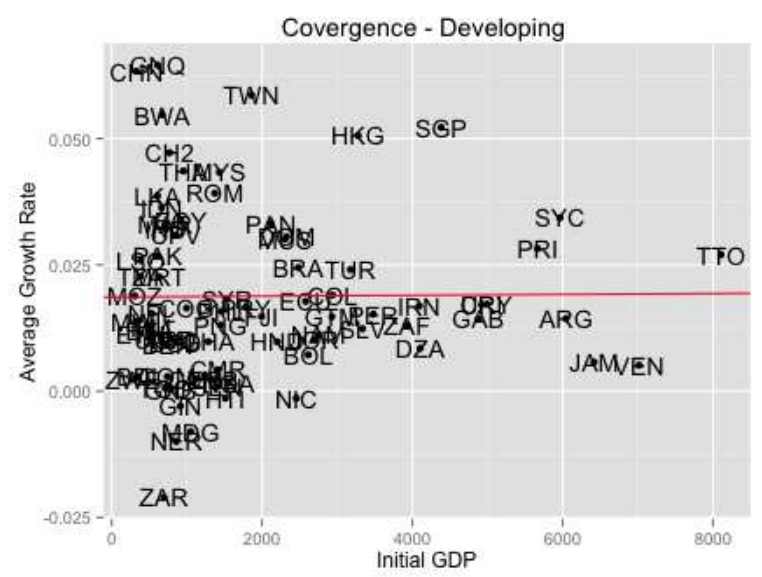

(b) Developing and Newly Industrialized Countries

Figure 9: Convergence - plots of average growth rates against initial income 1960-2010

\footnotetext{
${ }^{25}$ With reference to these graphs, the starting year is 1960 and the final, 2010.
} 
To present our results we introduce a very simple variant of the concept of convergence described above, to differentiate, we call it regime convergence. Regime convergence refers to the existence, during a specific regime of a country's growth pattern, of a negative correlation between the magnitude of growth performed within the regime and the level of GDP per capita registered at the beginning of the same regime. This concept implies catching up within specific phases of growth dynamics; in all other respects it mirrors exactly the $\beta$-convergence discussed above. Regimes are identified, as usual, by structural breaks and might be expansionary or recessionary according to the sign of the long run trend estimated within the regime itself. It is relevant to remark that, in order to study regime convergence, one must express the magnitude of growth in a way that omits the fact that different countries might experience (and usually they do) regimes of different length. Thus, we follow the same approach we adopted in section 3.3: growth magnitude is measured by the ratio between GDP per capita at the final and initial point of the regime under evaluation.

Figure 10 shows a scatter plot of growth magnitudes against initial levels of output per capita for all developing countries experiencing an expansionary 10a and a recessionary 10b selected regime. As it is possible to see by inspection, there is some evidence for convergence in the expansionary case and divergence for the recessionary one. Roughly speaking, such figures suggest that (i) during phases of positive growth, countries that are initially poorer grow at relatively higher paces and therefore, catch-up with the others. On the other hand (ii) during phases of negative growth it is the poorer countries that experience the worse recessions.

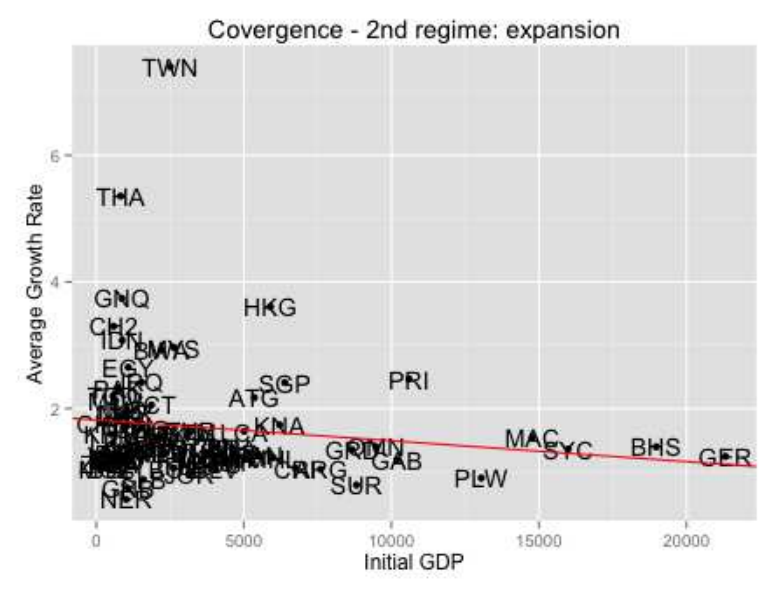

(a) Second Regime: Expansion

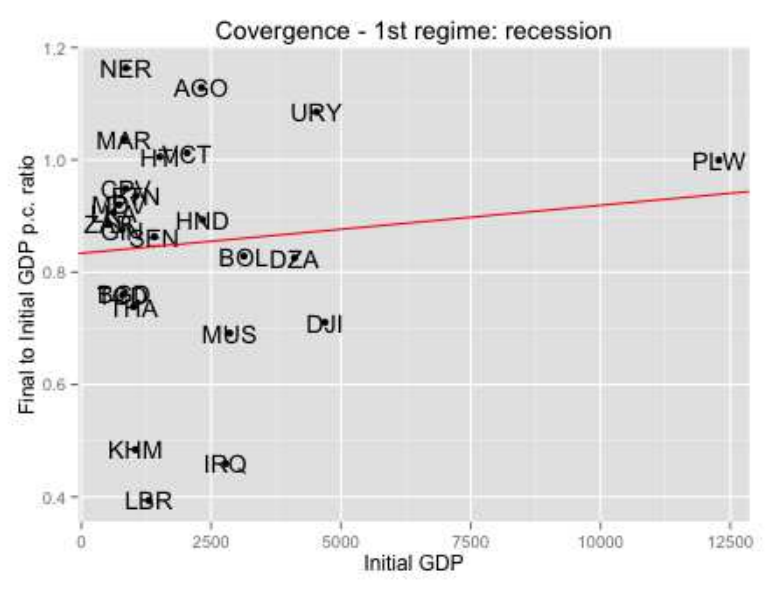

(b) First Regime: Recession

Figure 10: Regime convergence: first regime

To better explore the above findings we computed the correlations between growth and initial level of output (per capita) and estimated a simple regression model using the initial level of output as a covariate for growth's magnitude in all of the expansionary and recessionary regimes we identified. Results are collected in table 10. We should interpret them cautiously for two reasons. First, we scaled initial income in such a way that its marginal effect, $\beta^{*}$ can be interpreted as the change in the final to initial output 
ratio associated to an increase of 10.000 dollars in the regime's initial output. Hence, for example a coefficient $\beta^{*}=-5$ in an expansionary regime indicates that an increase of 10 thousand dollars in per capita GDP at the beginning of such regime corresponds to a final (at regime's end) GDP relative to initial levels that is $5 \%$ lower. Second, we did not run statistical tests but just reported the values we computed. This is because there are often very few countries within a given regime (for example, only 12 countries are found in recession in the third phase of their dynamics) implying a lack of power for any test. Furthermore, even though this issue is largely overlooked, finding an appropriate test would not be trivial since there is good evidence that output growth rates are fat tailed (see previous section and, in addition, Lee et al., 1998: Fagiolo et al., 2008: Castaldi and Dosi, 2009), implying the inadequateness of standard t-tests. Accordingly, we avoid placing much emphasis on the numbers we estimated; rather, we interpret more general evidence emerging from this exercise.

Table 10: Evidence of convergence in expansions and recessions.

\begin{tabular}{lcccc}
\hline Convergence in & \multicolumn{2}{c}{ expansion } & \multicolumn{2}{c}{ recession } \\
& $\beta^{*}$ & correlation & $\beta^{*}$ & correlation \\
\hline 1st regime & -3 & -0.02 & 8 & 0.11 \\
2nd regime & -34 & -0.14 & 0.6 & 0.003 \\
3rd regime & -23 & -0.11 & 1 & 0.03 \\
\hline
\end{tabular}

Note: for each country the three regimes correspond to the following periods $\left[t_{i n}, t_{1}\right),\left[t_{1}, t_{2}\right)$ and $\left[t_{2}, t_{f i n}\right)$ respectively.

Regimes of negative and positive growth display opposite behaviours in all three regimes. Expansionary phases are characterized by a negative correlation between initial richness and growth magnitude. This feature is in line with the convergence hypothesis. To the contrary, recessionary regimes never confirm such hypothesis. If anything, the data demonstrates that there is a tendency towards divergence during contractionary phases, since poorer countries suffer deeper recessions than relatively richer ones. By putting the two pieces of evidence together one finds that, in aggregate, there is no convergence at all in the developing world. One of the reasons for a lack of convergenece is precisely that developing countries experience growth dynamics that are mixed with long expansions and long recessions; while poorer countries tend to grow more in the former, they also face worst depressions in the latter. These results are confirmed when we investigate the convergence hypothesis within the classes identified by our taxonomy. In the case of Peaks we find a negative correlation between initial output levels and growth magnitude $\left(\beta^{*}=-30\right)$ and the same holds for Valleys $(-4)$ and Slopes $(-13)$, that is, for those categories experiencing much longer phases of expansion than recession. Instead, if we consider Abysses, Icebergs and Low Cliffs (both individually or grouped together) we obtain evidence supporting the divergence hypothesis (grouping, $\beta^{*}=+1$ ).

In sum, there is evidence that some convergence takes place during growth regimes, yet it does not within recessions. Thus, for a new phenomenon of aggregate convergence to take place, only few countries should move from their expansionary regimes to phases of negative growth. The likelihood of such an 
event is difficult to estimate, and the task goes beyond our purposes. However, the observation of past growth patterns experienced by developing countries tells us that a phase of recession is likely to follow an expansion. For example, the $34 \%$ of countries that experienced a first regime of growth moved to recession in the second regime. In addition, these countries were not stagnating in growth, but their average rate of growth in the first regime was quite high (3.3\%), remarkably larger than that of countries that kept growing in the second regime $(2.0 \%)$.

\section{Conclusions}

A satisfactory analysis of long run growth must be sensitive to heterogeneous patterns of growth. Especially for developing countries, growth is characterized by structural breaks that have the crucial trait of being turning points.

In this paper we have provided a methodology and a taxonomy that characterize growth patterns on the basis of the sequence of regimes they experience. In section 2 we gave ample evidence of the need to describe growth performances of developing countries in a different way with respect to existing attempts. We have argued that there are qualitative and important differences between the growth patterns of industrial and developing countries: while the former experience almost a linear growth dynamics, the latter undergo more extreme accelerations and decelerations. What matters in most developing countries is that long regimes of large positive growth are followed by long regimes of large negative growth or, vice versa. Indeed growth miracles and failures are typical features of developing countries.

We provided an answer to the question: how frequent are turning points in growth dynamics? We proved that turning points are so relevant to the description of growth patterns that any qualitative framework which neglects to focus on this fundamental element incurs in the fallacy of non-robustness. In particular, we have evaluated the analysis of Pritchett (2000) by adding 45 countries and a decade of growth experience to show that his classification based on one structural break is inadequate to summarize growth patterns, particularly for developing countries. We have seen that Pritchett's taxonomy pools together very heterogeneous behaviours, which should be separately treated. Our analysis clarifies that, in order to have substantial improvement in the qualitative description of growth patterns, it is not sufficient to characterize growth with one break. Dynamics are more complex, especially for developing countries where the relevant phenomena are the turning points since the alternation of positive and negative growth regimes are extremely frequent. Hence, by identifying shifts, we introduced an additional level of complexity through the presence of two structural breaks.

In section 3.2, we presented our original categorization of growth dynamics based on the sequence of turning points experienced by each country. We proved that our new taxonomy is appealing for two reasons: It allows us to characterize a larger and more complex set of patterns, including those with long run accelerations and decelerations; and, remarkably, it gives information on the frequency and type of transitions from recessions to expansions (and vice versa) keeping track of those previously experienced. 
We undertook an analysis of our taxonomy from different angles, describing the frequency of each category and the geographical positioning of the countries in the different categories. The study of the instability of growth was carried out within and across classes of growth patterns. In particular, certain relevant points came to the floor with respect to the relationship between growth and volatility: (a) long run volatility is not associated with groups of countries growing at lower paces; rather, it seems that fastgrowing groups are those exhibiting larger instability of growth over the long run; (b) short run volatility, on aggregate, is negatively correlated with growth, however (c) diverse patterns emerge which clearly differentiate expansionary periods from recessionary ones. Expansions are characterized by a strong positive correlation between growth and around-trend volatility. On the contrary, recessions portray a liner association between growth and around trend volatility that is less pronounced in magnitude and of opposite sign. Finally we addressed the topical issue of convergence, showing that, in a cross section framework, the existence of convergence or divergence is robustly linked to the type of regime (expansionary or recessionary) countries are experiencing. Pulling together our results we call for the need to take into account (both in policy-making and modelling efforts) that, in a comparative setting, poorer countries are those most adversely affected by the entrance in long phases of recession: they tend to fall behind even more and exhibit larger drops in output than richer countries. While poorer catch-up in good time, they suffer more in bad ones. Given the high frequency of turning points (especially from growth to recession) in the growth dynamics experienced by developing countries, further research and attention on their identification and prevention is needed. 


\section{References}

Auerbach, A. J. and Y. Gorodnichenko (2012a). Fiscal multipliers in recession and expansion. In Fiscal Policy after the Financial crisis, pp. 63-98. University of Chicago press.

Auerbach, A. J. and Y. Gorodnichenko (2012b). Measuring the output responses to fiscal policy. American Economic Journal: Economic Policy 4(2), pp. 1-27.

Bai, J. and P. Perron (1998). Estimating and Testing Linear Models with Multiple Structural Changes. Econometrica $66(1), 47-78$.

Bai, J. and P. Perron (2003). Computation and analysis of multiple structural change models. Journal of Applied Econometrics 18(1), 1-22.

Barro, R. J. (1991). Economic growth in a cross section of countries. The Quarterly Journal of Economics $106(2)$, pp. 407-443.

Ben-David, D. and D. H. Papell (1998). Slowdowns and meltdowns: Postwar growth evidence from 74 countries. The Review of Economics and Statistics 80(4), pp. 561-571.

Bottazzi, G. (2004). Subbotools users manual.

Braudel, F. (1973). Capitalism and material life, 1400-1800. New York: Haper and Row.

Buiter, W. and E. Rahbari (2011). Global growth generators: moving beyond emerging markets and bric. Technical report, Citigroup - Global Economics View.

Calvo, G. A. (2003). Explaining sudden stop, growth collapse, and bop crisis: The case of distortionary output taxes. IMF Staff Papers 50, pp. 1-20.

Calvo, G. A. (2005). Crises in emerging market economies: A global perspective. Technical report, National Bureau of Economic Research.

Calvo, G. A., A. Izquierdo, and R. Loo-Kung (2006a). Relative price volatility under sudden stops: the relevance of balance sheet effects. Journal of international Economics 69(1), 231-254.

Calvo, G. A., A. Izquierdo, and E. Talvi (2006b). Phoenix miracles in emerging markets: recovering without credit from systemic financial crises. Technical report, National Bureau of Economic Research.

Castaldi, C. and G. Dosi (2009). The patterns of output growth of firms and countries: Scale invariances and scale specificities. Empirical Economics 37(3), 475-495.

Cerra, V. and S. C. Saxena (2008). Growth dynamics: The myth of economic recovery. The American Economic Review 98(1), pp. 439-457. 
Cuberes, D. and M. Jerzmanowski (2009). Democracy, diversification and growth reversals. The Economic Journal 119(540), 1270-1302.

Diebold, F. X. and G. D. Rudebusch (1992). Have postwar economic fluctuations been stabilized? The American Economic Review 82(4), pp. 993-1005.

Dosi, G., C. Freeman, and S. Fabiani (1994). The process of economic development: Introducing some stylized facts and theories on technologies, firms and institutions. Industrial and Corporate Change 3(1), $1-45$.

Durlauf, S. N., P. Johnson, and J. Temple (2005). Growth econometrics. In P. Aghion and S. Durlauf (Eds.), Handbook of Economic Growth. Elsevier: Amsterdam.

Easterly, W., M. Kremer, L. Pritchett, and L. H. Summers (1993). Good policy or good luck? Journal of Monetary Economics 32(3), $459-483$.

Fagiolo, G., M. Napoletano, and A. Roventini (2008). Are output growth-rate distributions fat-tailed? some evidence from oecd countries. Journal of Applied Econometrics 23(5), pp. 639-669.

Fazzari, S. M., J. Morley, and I. Panovska (2015). State-dependent effects of fiscal policy. Studies in Nonlinear Dynamics \& Econometrics 19(3), 285-315.

Ferraresi, T., A. Roventini, and G. Fagiolo (2014). Fiscal policies and credit regimes: a tvar approach. Journal of Applied Econometrics 30, 104-1072.

Filardo, A. J. and S. F. Gordon (1998, July). Business cycle durations. Journal of Econometrics 85(1), 99-123.

Gallant, A. R. and W. A. Fuller (1973). Fitting segmented polynomial regression models whose join points have to be estimated. Journal of the American Statistical Association 68(341), pp. 144-147.

Gleditsch, N. P., P. Wallensteen, M. Eriksson, M. Sollenberg, and H. Strand (2002). Armed conflict 1946-2001: A new dataset. Journal of peace research 39(5), 615-637.

Harbom, L., E. Melander, and P. Wallensteen (2008). Dyadic dimensions of armed conflict, 19462007. Journal of Peace Research 45(5), 697-710.

Hausmann, R., L. Pritchett, and D. Rodrik (2005). Growth accelerations. Journal of Economic Growth 10(4), pp. 303-329.

Hausmann, R., F. Rodriguez, and R. Wagner (2008). Growth collapses. In C. Reinhart, C. Végh, and A. Velasco (Eds.), Money, Crises and Transition, pp. 376-428. The MIT Press: Cambridge.

Hawksworth, J. and A. Tiwari (2011). The world in 2050: The accelerating shift of global economic power: challenges and opportunities. Technical report, PWC. 
Islam, N. (1995). Growth empirics: A panel data approach. The Quarterly Journal of Economics 110(4), pp. $1127-1170$.

Jerzmanowski, M. (2006, December). Empirics of hills, plateaus, mountains and plains: A Markovswitching approach to growth. Journal of Development Economics 81(2), 357-385.

Jones, B. F. and B. A. Olken (2008). The anatomy of start-stop growth. Review of Economics and Statistics $90(3), 582-587$.

Krugman, P. R., K. M. Dominquez, and K. Rogoff (1998). It's baaack: Japan's slump and the return of the liquidity trap. Brookings Papers on Economic Activity 2, 137-205.

Lee, Y., L. A. N. Amaral, D. Canning, M. Meyer, and H. E. Stanley (1998). Universal features in the growth dynamics of complex organizations. Physical Review Letters 81(15), 3275.

Loayza, N. and V. V. Hnatkovska (2004). Volatility and growth. Technical Report 3184, World Bank Policy Research Working Paper.

Maddison, A. (2007). Fluctuations in the momentum of growth within the capitalist epoch. Cliometrica $1(2), 145-175$.

Mankiw, N. G., D. Romer, and D. N. Weil (1992). A contribution to the empirics of economic growth. The Quarterly Journal of Economics 107(2), pp. 407-437.

Morier, B. and V. K. Teles $(2015,12)$. A time-varying markov-switching model for economic growth. Macroeconomic Dynamics FirstView, 1-31.

Pritchett, L. (2000). Understanding patterns of economic growth: Searching for hills among plateaus, mountains, and plains. The World Bank Economic Review 14(2), 221-250.

Quah, D. (1993). Galton's fallacy and tests of the convergence hypothesis. The Scandinavian Journal of Economics 95(4), pp. 427-443.

Rappoport, P. and L. Reichlin (1989). Segmented trends and non-stationary time series. The Economic Journal 99(395), pp. 168-177.

Reddy, S. and C. Minoiu (2009). Real income stagnation of countries 1960-2001. Journal of Development Studies 45(1), 1-23.

Rodrik, D. (2011). The future of economic convergence. Technical report, National Bureau of Economic Research.

Silverman, B. (1986). Density Estimation for Statistics and Data Analysis. London: Chapman and Hall.

Spence, M. (2011). The next convergence: The future of economic growth in a multispeed world. Macmillan. 
Timmer, M. P. and G. J. de Vries (2009, June). Structural change and growth accelerations in Asia and Latin America: a new sectoral data set. Cliometrica, Journal of Historical Economics and Econometric History 3(2), 165-190. 


\section{Appendix}

Here we show the table collecting all breaks identified to characterize countries' growth patterns according to the classification we proposed. Note that for the few cases we only identified one break, the reason is that either the distance between the fist and the second breaks or between one break and the initial/final sample' date was less than 5 years.

Table 11: Countries and their structural breaks (I)

\begin{tabular}{|c|c|c|c|c|c|}
\hline Country & First Break & Second Break & Country & First Break & Second Break \\
\hline & Africa & & & Africa & \\
\hline Angola & 1996 & 2005 & Somalia & 1979 & 1994 \\
\hline Benin & 1976 & 1987 & South Africa & 1976 & 1992 \\
\hline Bhutan & 1976 & 1993 & Sudan & 1976 & 1996 \\
\hline Botswana & 1971 & 1989 & Tanzania & 1973 & 2000 \\
\hline Burkina Faso & 1972 & 1996 & Togo & 1970 & 1981 \\
\hline Burundi & 1970 & 1995 & Uganda & 1969 & 1986 \\
\hline Cameroon & 1978 & 1991 & Zaire & 1990 & 2000 \\
\hline Cape Verde & 1967 & 1975 & Zambia & 1967 & 1995 \\
\hline Centr. Afr. Rep. & 1990 & & Zimbabwe & 1970 & 1993 \\
\hline Chad & 1979 & 2004 & & & \\
\hline Comoros & 1968 & 1983 & \multicolumn{3}{|c|}{ Asia, Pacific and Oceania } \\
\hline Congo & 1977 & 1985 & Bangladesh & 1977 & 1996 \\
\hline Côte D' Ivoire & 1980 & & Barbados & 1969 & 1997 \\
\hline Djibouti & 1978 & 1991 & Brunei & 1981 & 1987 \\
\hline Equat. Guinea & 1979 & 1997 & Cambodia & 1982 & 1995 \\
\hline Ethiopia & 1974 & 2002 & China & 1971 & 1976 \\
\hline Gabon & 1971 & 1978 & Fiji & 1971 & 1983 \\
\hline Gambia & 1981 & 1995 & Hong Kong & 1967 & 1989 \\
\hline Ghana & 1970 & 1983 & India & 1979 & 2002 \\
\hline Guinea & 1970 & 1998 & Indonesia & 1970 & 1998 \\
\hline Guinea-Bissau & 1975 & 1998 & Kiribati & 1976 & 1983 \\
\hline Lesotho & 1977 & 1985 & Laos & 1981 & 2003 \\
\hline Liberia & 1990 & 1997 & Macao & 1980 & 1998 \\
\hline Madagascar & 1978 & 2002 & Maldives & 1976 & 1984 \\
\hline Malawi & 1981 & 2003 & Malaysia & 1971 & 1994 \\
\hline Mali & 1964 & 1976 & Marshall Islands & 1976 & 1997 \\
\hline Mauritania & 1970 & 2006 & Micronesia & 1976 & 1994 \\
\hline Mauritius & 1971 & 1980 & Mongolia & 1981 & 1992 \\
\hline Mozambique & 1983 & 1994 & Nepal & 1986 & 1998 \\
\hline Namibia & 1972 & 1993 & Palau & 1984 & 1993 \\
\hline Niger & 1965 & 1984 & Papa New Guinea & 1976 & 1992 \\
\hline Nigeria & 1971 & 1995 & Philippines & 1984 & 1998 \\
\hline Rowanda & 1994 & & Samoa & 2000 & \\
\hline Sao Tome and Prin. & 1981 & 2001 & Singapore & 1968 & 1980 \\
\hline Senegal & 1975 & 1993 & Solomon Islands & 1982 & 2000 \\
\hline Sey Shelles & 1978 & 2003 & Sri Lanka & 1959 & 1978 \\
\hline Sierra Leone & 1988 & 1997 & Taiwan & 1964 & 1995 \\
\hline South Africa & 1976 & 1992 & Thailand & 1959 & 1990 \\
\hline
\end{tabular}


Table 12: Countries and their structural breaks (II)

\begin{tabular}{|c|c|c|c|c|c|}
\hline Country & First Break & Second Break & Country & First Break & Second Break \\
\hline \multicolumn{3}{|c|}{ Asia, Pacific and Oceania } & \multicolumn{3}{|c|}{ Latin America and Caribbean } \\
\hline Tonga & 1981 & 2003 & Saint Lucia & 1976 & 1988 \\
\hline Vanuatu & 1976 & 2001 & Puerto Rico & 1974 & 2000 \\
\hline \multirow[t]{2}{*}{ Viet Nam } & 1976 & 1988 & Suriname & 1990 & 1999 \\
\hline & & & Trinidad and Tob. & 1983 & 1993 \\
\hline Europe & & & Uruguay & 1973 & 1982 \\
\hline Albania & 1991 & 1998 & Venezuela & 1980 & 2001 \\
\hline Bulgaria & 1989 & 1998 & & & \\
\hline Romania & 1981 & 1991 & & & \\
\hline & & & \multicolumn{3}{|c|}{ Middle East and North Africa } \\
\hline \multicolumn{3}{|c|}{ Latin America and Caribbean } & Afghanistan & 1987 & 2002 \\
\hline Antigua & 1976 & 1990 & Algeria & 1967 & 1991 \\
\hline Argentina & 1981 & 2002 & Bahrain & 1976 & 1985 \\
\hline Bahamas & 1977 & 1991 & Egypt & 1975 & 1992 \\
\hline Barbados & 1969 & 1997 & Iran & 1977 & 1990 \\
\hline Belize & 1983 & 1989 & Iraq & 1991 & 2002 \\
\hline Bermuda & 1990 & 2002 & Jordan & 1968 & 1989 \\
\hline Bolivia & 1959 & 1983 & Lebanon & 1976 & \\
\hline Brazil & 1971 & 1981 & Morocco & 1961 & 1981 \\
\hline Chile & 1961 & 1992 & Oman & 1976 & 1987 \\
\hline Colombia & 1972 & 1999 & Pakistan & 1963 & 1997 \\
\hline Costa Rica & 1981 & 1991 & Syria & 1975 & 1986 \\
\hline Cuba & 1988 & 1995 & Tunisia & 1972 & 1986 \\
\hline Dominica & 1988 & 2002 & Turkey & 1960 & 1980 \\
\hline Ecuador & 1973 & 1983 & & & \\
\hline El Salvador & 1980 & 1992 & & & \\
\hline Grenada & 1990 & 1997 & & & \\
\hline Guatemala & 1963 & 1983 & & & \\
\hline Guyana & 1976 & 1992 & & & \\
\hline Haiti & 1976 & 1992 & & & \\
\hline Honduras & 1963 & 1983 & & & \\
\hline Jamaica & 1975 & 1989 & & & \\
\hline Nicaragua & 1979 & 1988 & & & \\
\hline Panama & 1980 & 2002 & & & \\
\hline Paraguay & 1970 & 1978 & & & \\
\hline Peru & 1976 & 1989 & & & \\
\hline Saint Vincent & 1976 & 1989 & & & \\
\hline Saint Kitts & 1988 & 2005 & & & \\
\hline
\end{tabular}



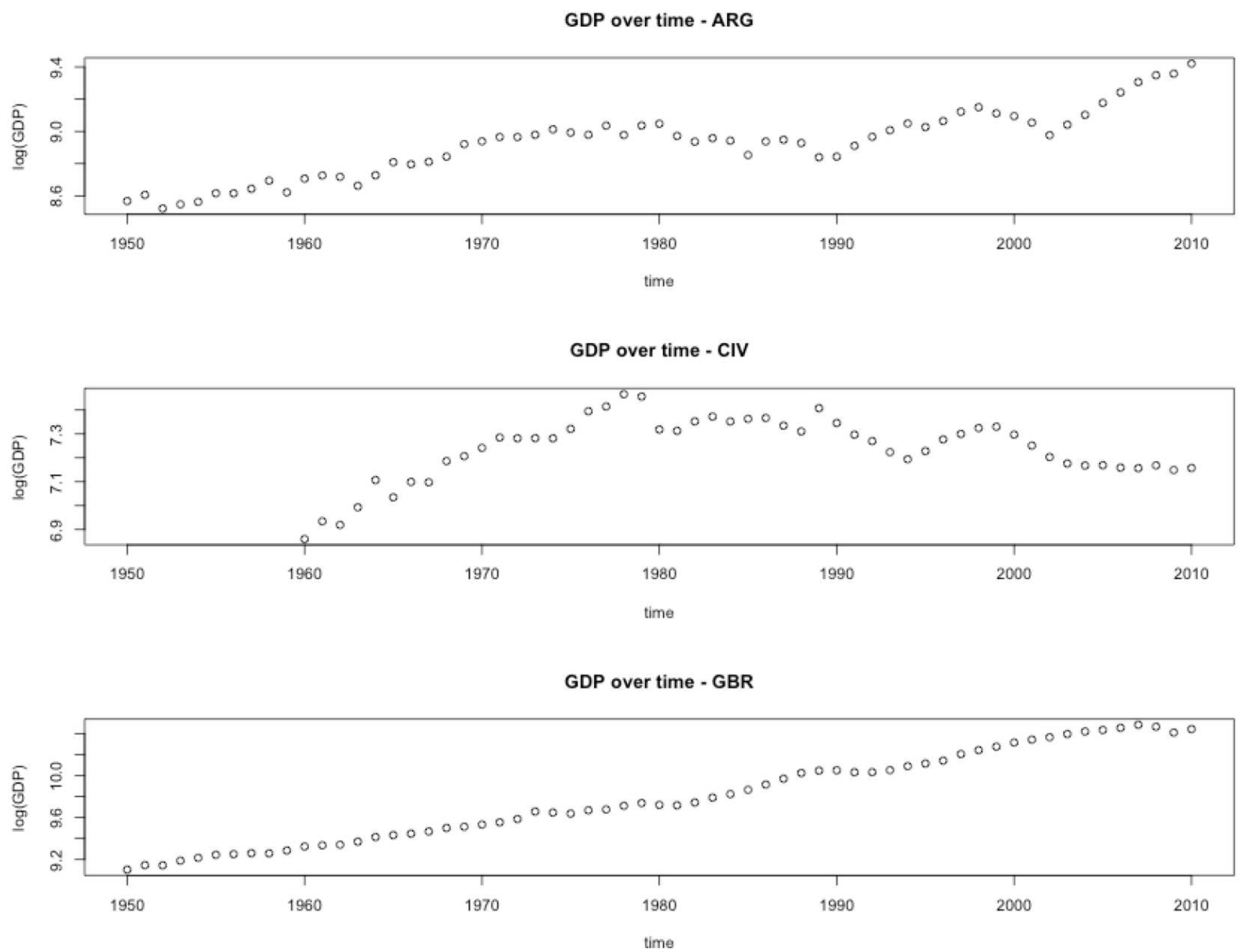

Figure 11: Example of Pritchett (2000)'s Mountains, logarithms of GDP per capita 